\title{
CD19+IgM+ cells demonstrate enhanced therapeutic efficacy in type 1 diabetes mellitus
}

\author{
Andrew D. Vonberg, ${ }^{1}$ Maria Acevedo-Calado, ${ }^{1}$ Aaron R. Cox, ${ }^{1,2}$ Susan L. Pietropaolo, ${ }^{1}$ \\ Roberto Gianani, ${ }^{1}$ Steven K. Lundy, ${ }^{3}$ and Massimo Pietropaolo ${ }^{1}$ \\ 'Diabetes Research Center, Division of Diabetes, Endocrinology and Metabolism Department of Medicine, and \\ ${ }^{2}$ Department of Molecular and Cellular Biology, Baylor College of Medicine, Houston, Texas, USA. ${ }^{3}$ Division of \\ Rheumatology, Department of Internal Medicine, University of Michigan Medical School, Ann Arbor, Michigan, USA.
}

\begin{abstract}
We describe a protective effect on autoimmune diabetes and reduced destructive insulitis in NOD.scid recipients following splenocyte injections from diabetic NOD donors and sorted CD19+ cells compared with NOD.scid recipients receiving splenocytes alone. This protective effect was age specific (only CD19+ cells from young NOD donors exerted this effect; $P<0.001$ ). We found that the $\mathrm{CD}^{+}{ }^{+} \mathrm{IgM}{ }^{+}$cell is the primary subpopulation of $B$ cells that delayed transfer of diabetes mediated by diabetogenic $T$ cells from NOD mice $(P=0.002)$. Removal of $/ \mathrm{gM}^{+}$cells from the $\mathrm{CD}_{19}{ }^{+}$pool did not result in protection. Notably, protection conferred by $\mathrm{CD} 19^{+} \mathrm{IgM} \mathrm{M}^{+}$cotransfers were not dependent on the presence of Tregs, as their depletion did not affect their ability to delay onset of diabetes. Blockade of IL-10 with neutralizing antibodies at the time of $\mathrm{CD} 19+$ cell cotransfers also abrogated the therapeutic effect, suggesting that IL-10 secretion was an important component of protection. These results were strengthened by ex vivo incubation of $\mathrm{CD} 19^{+}$cells with IL-5, resulting in enhanced proliferation and IL-10 production and equivalently delayed diabetes progression $(P=0.0005)$. The potential to expand $\mathrm{CD} 9^{+} \mid \mathrm{IM}^{+}$cells, especially in response to IL-5 stimulation or by pharmacologic agents, may be a new therapeutic option for type 1 diabetes.
\end{abstract}

Conflict of interest: The authors have declared that no conflict of interest exists.

License: Copyright 2018, American Society for Clinical Investigation.

Submitted: January 23, 2018 Accepted: October 31, 2018 Published: December 6, 2018

\section{Reference information:} JCI Insight. 2018;3(23):e99860. https://doi.org/10.1172/jici. insight.99860.

\section{Introduction}

Strong evidence indicates that an imbalance between autoreactive and Tregs plays a key role in pathogenesis of type 1 diabetes (T1D) in animal models (1-3), as well as in humans (4-6). The initiation of this disease is dependent on the activity of both $\mathrm{CD} 4^{+}$and $\mathrm{CD} 8^{+} \mathrm{T}$ cells (7-12), with evidence of Tregs modulating the onset of diabetes in both NOD mice and humans (13-15). While it is clear that T cells are the primary effectors of pathogenesis in T1D $(16,17)$, increasing evidence also supports an important role for B cells in disease development, both as autoantibody producers and antigen presenters (18-21).

B cells play a fundamental role in autoimmune disorders $(22,23)$. Antibodies specific for insulin and other pancreatic autoantigens are well-documented hallmarks of T1D (24). In patients with recent onset of T1D, depletion of B cells with anti-CD20 therapy slowed the decline of islet $\beta$ cell function, although long-term effects were less robust $(25,26)$. Hence, evidence for the contribution of B cells to T1D is clear; however, their specific mechanisms of promoting disease pathogenesis requires further investigation.

Similar to T cell compartment, some B lymphocyte subsets act as crucial regulators in autoimmune disorders (27-31). Our results suggest that a change in the regulatory capacity of B cells is a major contributor to diabetes development and progression.

In particular, we investigated age-related differences in the ability of B cells to control diabetes development in an adoptive transfer model using NOD.scid recipient mice. Adoptive transfer experiments using splenocytes from diabetic NOD female donors into immunodeficient syngeneic recipients, NOD.scid mice, were performed to assess whether diabetes progression was affected by the presence or absence of CD19+ cells $(32,33)$. B cells from younger NOD mice conferred protection, while those from older counterparts were ineffective. Differences were found between $\operatorname{IgM}^{+}$and $\mathrm{IgM}^{-}$B cell subsets. IL-10 was an important factor in protection in a Treg-independent manner, and IL-5 stimulation in vitro enhanced the proliferation and IL-10 production of B cells from young NOD mice. These data provide the foundation for studying 
changes in the functions of regulatory B cells over time and a potentially novel mechanism for inducing the suppressive capabilities of regulatory B cells using IL-5-induced IL-10 production.

\section{Results}

Diabetes is significantly delayed in an adoptive transfer model following injections of $M H C$-compatible CD19+ cells from young donor NOD mice. Splenocytes isolated from MHC-compatible diabetic female NOD mice were i.v. injected into 6-week-old NOD.scid recipient female mice. NOD.scid recipients receiving single transfers of diabetic splenocytes started to develop T1D at day 20 after transfer (Figure 1A). Cotransfer experiments were performed on day 6 and day 12 using CD19+ cells purified from 6 -week-old prediabetic female NOD mice to create a boosted $\mathrm{B}$ cell pool mimicking the young prediabetes phase of the NOD donor. We observed a strikingly significant delay in progression to autoimmune diabetes in NOD.scid recipients when purified splenic $\mathrm{CD}_{19}{ }^{+}$cells from 6-week-old NOD mice were cotransferred (Figure 1A; $P<0.0001$ ). By day 40 after transfer, $100 \%$ of the NOD.scid recipients receiving diabetic splenocytes alone had progressed to overt diabetes, while $100 \%$ of NOD.scid CD $19^{+}$cotransfer recipients were still normoglycemic (Figure 1A). CD4 and $\mathrm{CD} 8^{+} \mathrm{T}$ cell populations (gated initially on $\mathrm{CD}^{+} \mathrm{CD} 19^{-}$) were not significantly different after the reconstitution process in NOD.scid recipients receiving either NOD splenocytes alone or CD19+ ${ }^{+}$cotransfers (Figure 1B). Further analysis of the B cells from 6-week-old NOD female mice and matching C57BL/6 and $\mathrm{Balb} / \mathrm{c}$ controls found that NOD mice have an increased number of $\mathrm{CD} 19^{+} \operatorname{IgM}^{+} \mathrm{CD} 5^{\text {hi }} \mathrm{CD} 1 \mathrm{~d}^{\text {lo }}$ traditionally described as Bregs in NOD mice as compared with control strains (Figure 1C) (34-37). Analysis of the $\mathrm{CD}^{+} \mathrm{CD}^{+} \mathrm{Th}$ repertoire within the spleen revealed a normal distribution of Th1 (IFN- $\gamma$-secreting) and Th17 (IL-17A-secreting) T cells, with most of the T cells in the spleen of both NOD.scid recipient populations containing a majority of Th1 pool (Figure 1D), as established in the literature $(38,39)$.

To investigate the possible effect of age, cotransfer experiments were executed by using splenocytes from diabetic NOD donors combined with $\mathrm{CD} 19^{+} \mathrm{B}$ cells from either 6-week- or $>15$-week-old nondiabetic female NOD mice (15). While a similar delay in onset as the previous experiment was observed when $\mathrm{CD}_{19}{ }^{+}$cells from young donors were cotransferred, NOD.scid recipients of CD19+ ${ }^{+}$cells from $>15$-week-old nondiabetic NOD donors had a similar rate of diabetes progression compared with recipients of splenocytes alone obtained from NOD diabetic donors (Figure 2A). These are the first observations to our knowledge demonstrating that $>15$-week-old NOD female donors can transfer diabetes within the same amount of time as an already-diabetic NOD female donor. Further analysis of the CD19+ $\mathrm{B}$ cell pool taken from the spleen (Figure $2 \mathrm{~B}$ ) found an increased number of antigen-presenting capable marginal zone (MZ) B cells (48.4\%) and MZ precursors $(16.7 \%)$ as a percentage of the total $\mathrm{CD} 19^{+} \operatorname{IgM}^{\mathrm{hi}}$ $\mathrm{B}$ cell population in the young prediabetic NOD female mice, as compared with older $>15$-week-old NOD mice whose B cell repertoire skewed more highly to an antibody-producing follicular (FO) (54.5\%) phenotype, with significantly fewer MZ (15.7\%).

Concurrent with the development of $\mathrm{T} 1 \mathrm{D}$, insulitis was significantly reduced following cotransfer of $\mathrm{CD} 19^{+}$cells as compared with diabetic control transfers. The administration of splenocytes from a NOD diabetic donor, in addition to $\mathrm{CD} 19^{+}$cells from 6-week-old NOD donors, resulted in decreased severity of insulitis as compared with adoptive transfers involving splenocytes alone from a NOD diabetic donor (Figures 3, A-D). Insulitis scoring analysis showed that there were major differences between recipient groups observed at both ends of the scoring scale (scores of 1 versus 4), with the mice receiving CD19 ${ }^{+}$cells from 6-week-old donors having significantly more islets with little to no insulitis as compared with the other treatment options $(P=0.005)$, as well as fewer statistically significant islets scoring a 4 with greater than $50 \%$ islet infiltration $(P<0.0001)$ (Figure 3E).

We then measured proinflammatory cytokines IL-1 $\beta$, TNF- $\alpha$, IFN- $\gamma$, and IL-17 (Figures 3, F-I), as well as $\mathrm{Th}_{2}$-mediated and antiinflammatory cytokines IL-4 and IL-10 (Supplemental Figure 1, C and D; supplemental material available online with this article; https://doi.org/10.1172/jci.insight.99860DS1) (40). NOD.scid recipients receiving splenocytes and $\mathrm{CD} 19^{+}$cells from a 6-week-old NOD donor had no measurable IL-1 $\beta$ level as compared with any other transfer group (Figure 3F; $P<0.001$ ). Conversely, we found no significant differences in circulating IL-1 $\beta$ in NOD.scid recipients of $>15$-week-old CD19+ cells compared with mice that received MHC-compatible splenocytes from diabetic mice only. We also looked at unstimulated IL-10 secretion, and we found no detectable serum levels of IL-10 (Supplemental Figure 1D). In combination with the IL-1 $\beta$ results, we assessed the presence of macrophages to determine whether the undetectable IL-1 $\beta$ level was related to a reduced macrophage pool (41). 
A

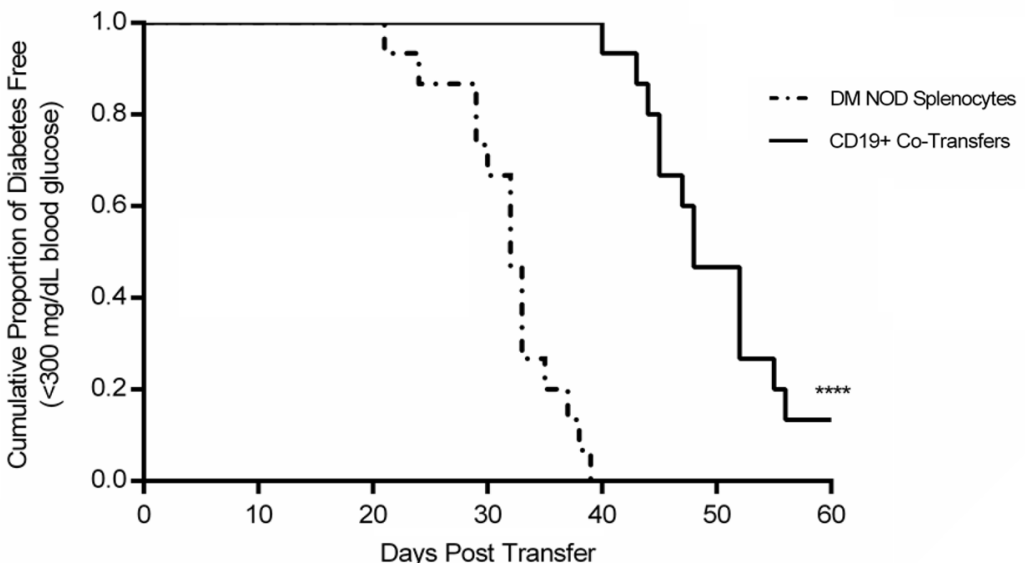

B

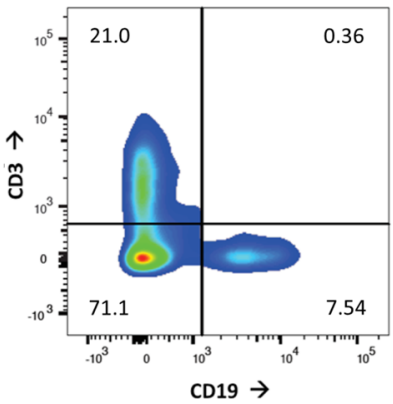

$\begin{array}{llllllll}\text { Spl Only } & 22 & 22 & 22 & 15 & 0 & 0 & 0 \\ \begin{array}{l}\text { CD19+ } \\ \text { Co-transfers }\end{array} & 22 & 22 & 22 & 22 & 22 & 12 & 5\end{array}$
0

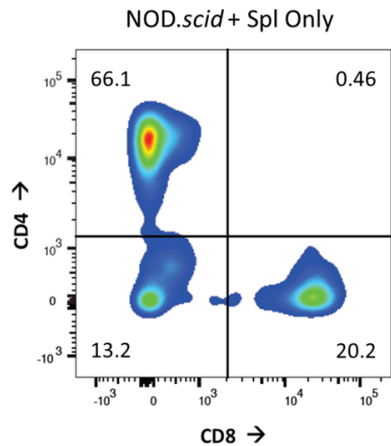

$\mathrm{CD} 8 \rightarrow$

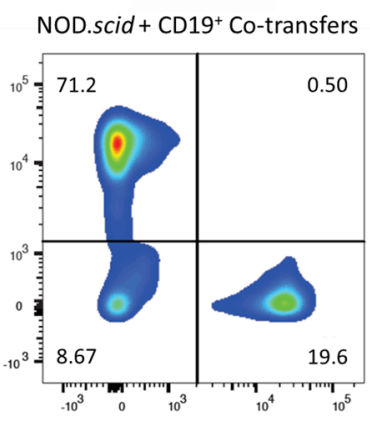

$\mathrm{CD} 8 \rightarrow$

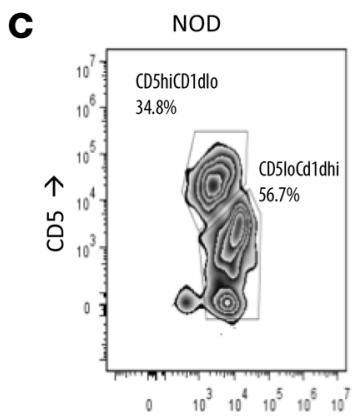

CD1d $\rightarrow$

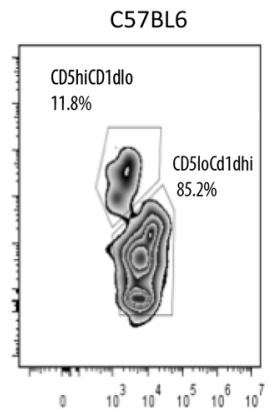

$\mathrm{CD} 1 \mathrm{~d} \rightarrow$

BALBC

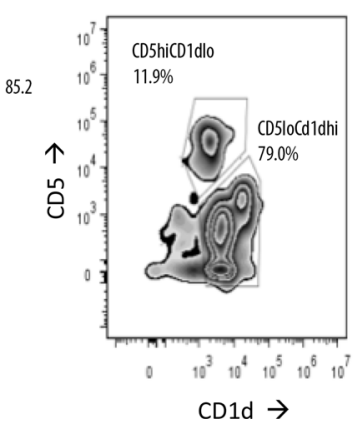

D

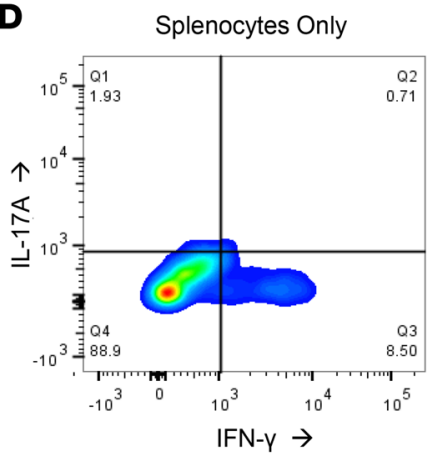

CD19+ Co-Transfers

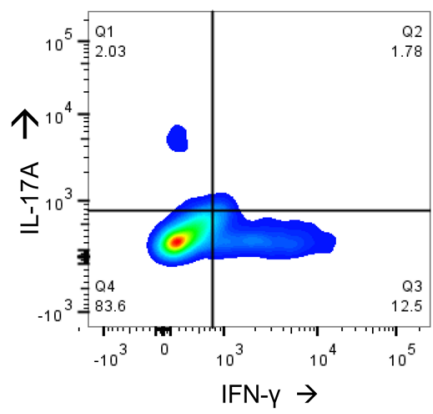

Figure 1. Adoptive transfer of diabetes is significantly delayed in the presence of purified CD19+ cell cotransfers. (A) Survival plots for comparison between female NOD.scid mice $(n=44)$ receiving splenocytes taken from a diabetic NOD female donor $(n=22$, dashed line), or the same splenocytes plus bead-purified CD19+ cells from 6-week-old prediabetic NOD female mice ( $n=22$, solid line). Results analyzed using the Mantel-Cox Log Rank test for survivability ( $\left.{ }^{* * *} P<0.0001\right)$. (B) Representative staining of reconstitution after adoptive transfer with CD3 and CD19 markers on splenocytes from NOD.scid transfer recipients. Cells initially gated on CD3 ${ }^{+}$CD19- to illustrate differences in CD4 and CD8 specific T cell populations. (C) Flow analysis of traditional regulatory B cell markers using 6-week-old female NOD, C57BL/6, and Balb/c mice. Splenocytes were gated on CD19+/gM+ cells and then stained for CD5 and CD1d. (D) Intracellular T cell levels after 6 hours of stimulation with PMA and lonomycin. Splenocytes from NOD.scid recipients following adoptive transfers were analyzed for resulting $\mathrm{T}$ cells by gating on $\mathrm{CD}^{+} \mathrm{CD}^{+}$and then intracellularly gating on IFN- $\gamma$ and IL-17A .

M1 macrophages, which are important for islet destruction during the autoimmune attack, were gated as $\mathrm{CD} 11 \mathrm{c}^{-} \mathrm{CD} 16 / 32^{+} \mathrm{Mac}-1^{+} \mathrm{F} 4 / 80^{+}$(Supplemental Figure $1 \mathrm{~A}$ ). The percentages across the different treatment groups were converted to total cell number by normalizing to the overall splenocyte counts and compared against one another. We found no statistically significant difference in the resulting M1 macrophage pool, whether NOD.scid recipients had received 6-week-old donor CD19+ cells, $\mathrm{CD}_{19^{+}}$cells from $>15$-week-old NOD mice, or diabetic splenocytes only (Supplemental Figure 1B). 
A

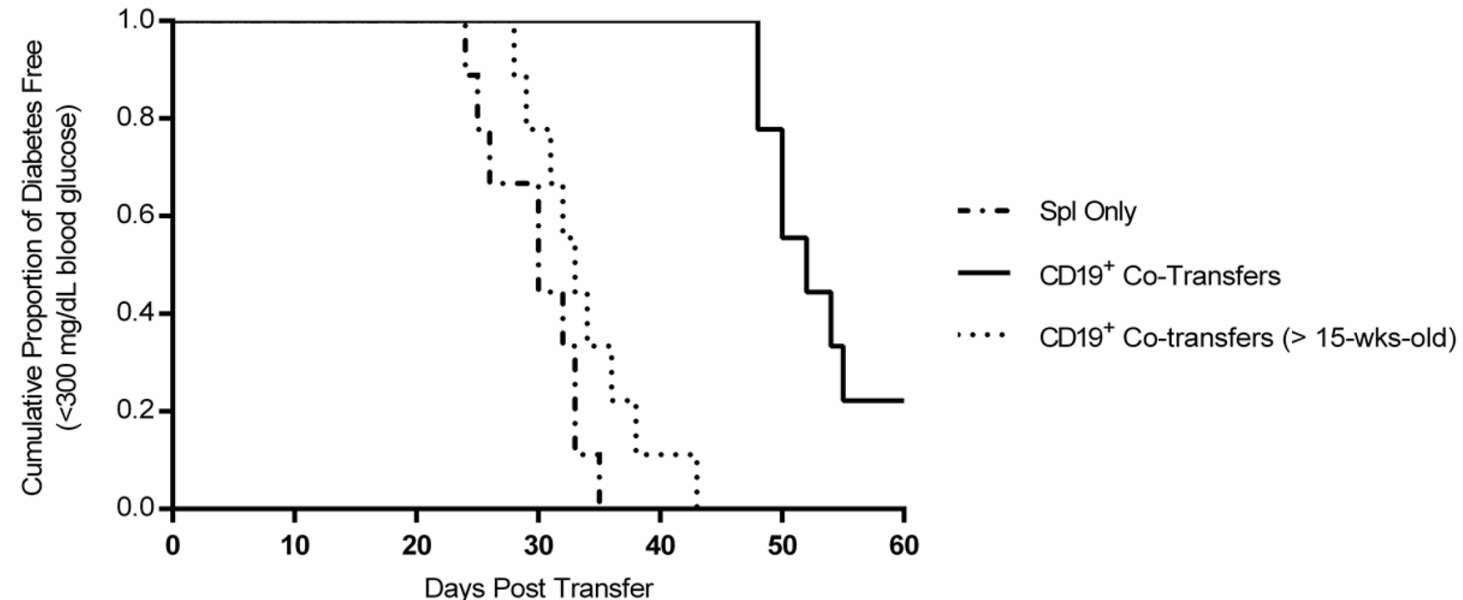

\begin{tabular}{|c|c|c|c|c|c|c|}
\hline Spl Only & 9 & 9 & 9 & 5 & 0 & 0 \\
\hline $\begin{array}{l}\text { CD19+ } \\
\text { Co-transfers }\end{array}$ & 9 & 9 & 9 & 9 & 9 & 5 \\
\hline CD19+ & & & & & & \\
\hline $\begin{array}{l}\text { Co-transfers } \\
(>15 \text {-wks-old) }\end{array}$ & 8 & 8 & 8 & 6 & 0 & 0 \\
\hline
\end{tabular}

\section{B} 5-week-old CD19+ cells

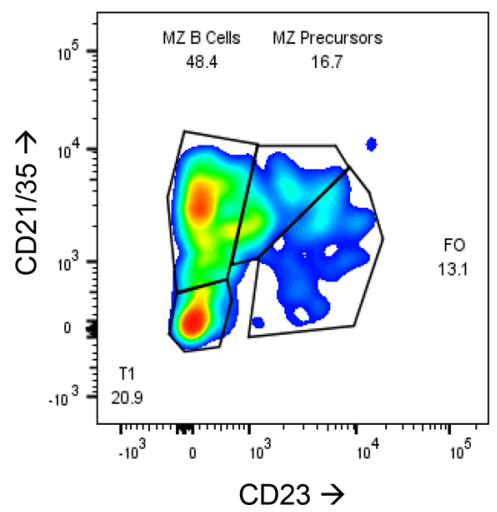

16-week-old CD19+ cells

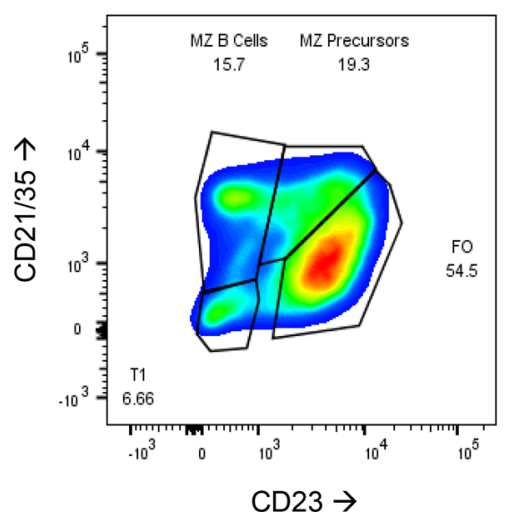

Figure 2. Age of the CD19+ cell pool affects ability to delay diabetes onset after adoptive cotransfers. (A) Survival curve comparing female NOD.scid mice $(n=26)$ receiving splenocytes from a diabetic NOD female donor $(n=9$, dashed line), splenocytes and purified CD19+ cells from 6-week-old NOD female donors ( $n=9$, solid line), and splenocytes plus purified CD19+ cells from female NOD donors older than 15 weeks $(n=8$, dotted line). Group comparisons performed using the Mantel-Cox Log Rank test for survivability (DM NOD vs. 6-wk-old CD19+, $P=0.0002$; DM NOD vs. $>15$-week-old CD19+, $P=0.0976$; and 6-week-old CD19+ vs. $>15$-week-old CD19+ $P=<0.0001$ ). (B) B cell repertoire of CD19+|gM+ cells spleen of NOD female mice at either 5 weeks or 16 weeks of age. Cells initially gated on $\mathrm{CD}^{-} \mathrm{g}^{+} \mathrm{gM}^{+}$and then subgated by CD21/35 and CD23.

These data suggest that the changes in peripheral IL-1 $\beta$ are not due to a lack of available macrophages in the 6-week-old CD19+ cell cotransfer recipients.

The $C D 19^{+} \mathrm{IgM}^{+}$cell is the primary cell subpopulation of B cells that delayed adoptive transfer of diabetes mediated by diabetogenic T cells from NOD mice. In order to further study the effects of the 6-week-old CD19+ cell pool, adoptive transfers of NOD splenocytes from diabetic donors into 6-week-old NOD.scid recipients were evaluated using a dual selection mechanism whereby splenocytes from 6-week-old female NOD mice were selected as $\mathrm{CD} 19^{+}$cells and were then purified again to separate out the $\operatorname{IgM}^{+}$and $\operatorname{IgM}^{-}$subgroup of $\mathrm{CD} 19^{+}$cells. We were able to increase the $\mathrm{CD}^{1} 9^{+} \mathrm{IgM}^{+}$pool, while our $\mathrm{CD} 19^{+} \mathrm{IgM}^{-}$control transfers had nearly complete removal of the $\mathrm{IgM}^{+}$population (data not shown). This protocol had the added benefit of further separating mature FO B cells with low IgM expression away from mucosal B-1 B cells, immature B cells, and marginal zone (MZ) B cells that have higher surface IgM expression $(42,43)$. NOD.scid recipients were followed for 

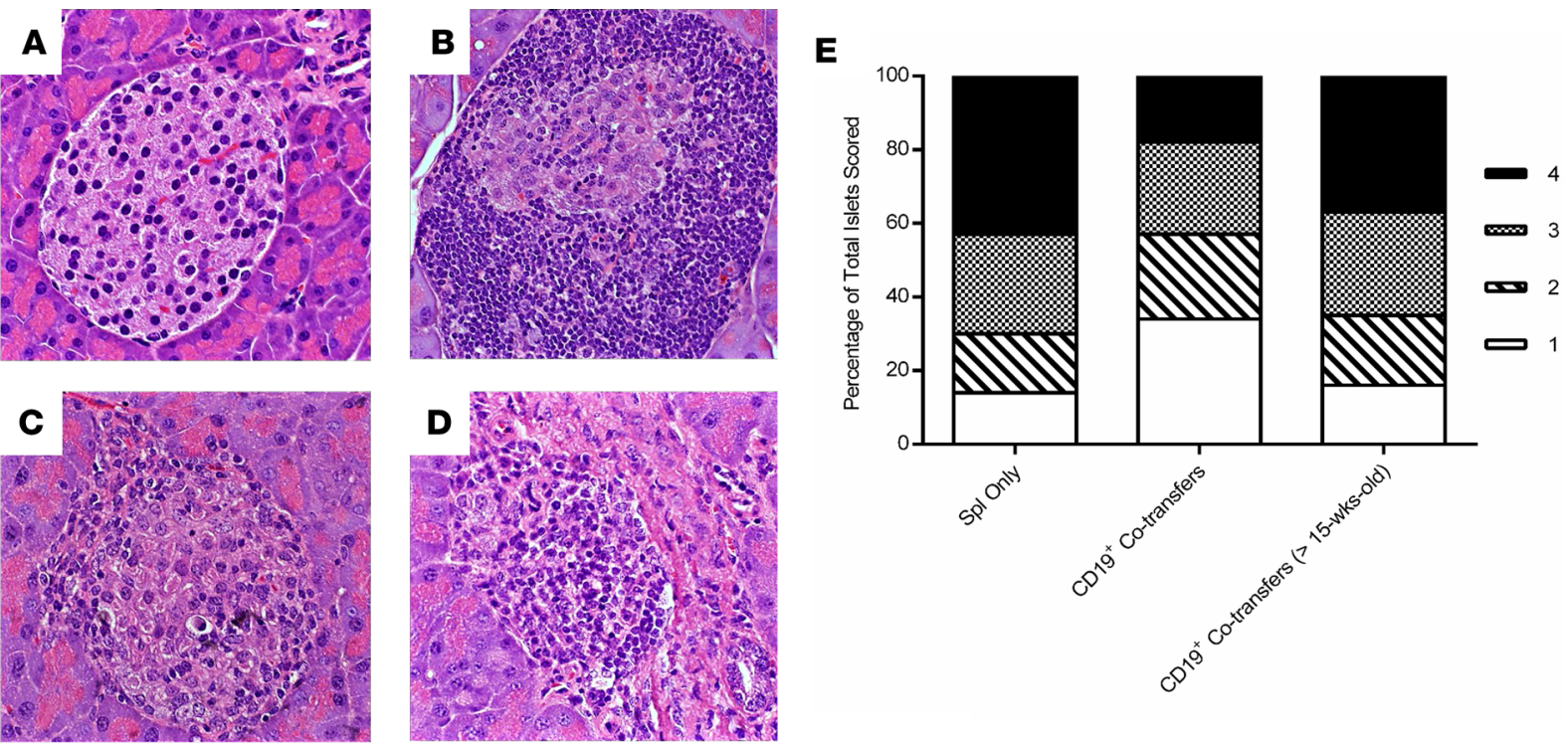

G
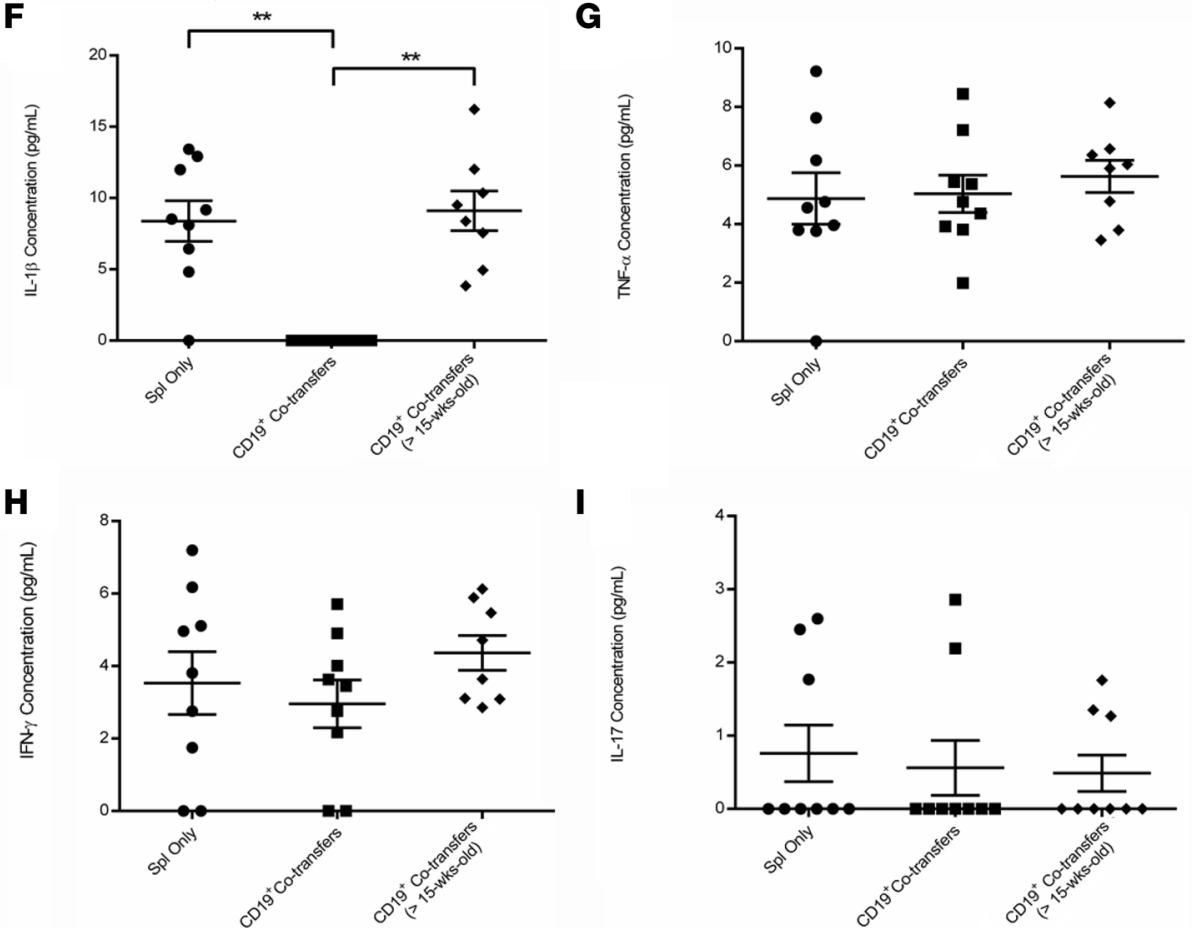

Figure 3. CD19+ cells cotransferred from 6-week-old NOD donors into NOD.scid recipients leads to decreased islet infiltration. Representative islets for each group after staining with H\&E. Images captured at 40x magnification. (A) Untreated 10-week-old NOD.scid female. (B) Diabetic NOD.scid recipient receiving only splenocytes from a diabetic NOD female donor. (C) Diabetic NOD.scid recipient receiving cotransfers of diabetic splenocytes and CD19+ cells purified from a 6-week-old prediabetic NOD female. (D) Diabetic NOD.scid recipient receiving cotransferred diabetic splenocytes and $\mathrm{CD}_{19}{ }^{+}$cells from a NOD female mouse older than 15 weeks of age. (E) Insulitis scoring results from pancreatic sections stained with H\&E of NOD.scid recipients that received either diabetic splenocytes $(n=9$ mice), splenocytes cotransferred with bead-purified CD19+ cells from 6-week-old NOD donors ( $n=9$ mice), or splenocytes cotransferred with CD19+ cells purified from $>15$-week-old NOD female donors $(n=8$ mice). Islets were individually scored on a 1-4 scale of increasing insulitis severity, and the percentage of each score as a part of the whole was graphically represented. Islets scoring a 1 resulted in $P=0.0051$, and islets scoring a 4 resulted in $P<0.0001$ when compared using $2 \times 2$ contingency tables and a $\chi^{2}$ analysis. Serum was collected from NOD.scid recipients receiving either splenocytes from a diabetic NOD donor, diabetic splenocytes and CD19+ cells from 6-week-old NOD donors, or splenocytes from a diabetic NOD donor with CD19+ cells from $>15$-week-old NOD donors. The presence of (F) IL-1 $\beta$, (G) TNF- $\alpha$, (H) IFN- $\gamma$, (I) IL-17 was measured by ELISAs across the multiple treatment groups (** $P=0.02$ ). 
onset of diabetes by blood glucose measurement and underwent the same endpoint analyses as during the other cotransfer experiments. We observed that dual-selected $\mathrm{CD} 19^{+} \operatorname{IgM}^{+}$cells resulted in a significant delay in diabetes onset in NOD.scid mice when compared with recipients that received splenocytes from a diabetic NOD donor (Figure 4A; $P=0.002$ ). In contrast, removal of the $\mathrm{IgM}^{+}$subset of $\mathrm{CD} 19^{+}$cells, as seen in the $\mathrm{CD}^{+} 9^{+} \mathrm{IgM}^{-}$dual-selected group, ablated the protection conferred by the combined $\mathrm{CD} 19^{+}$pool of cells.

Insulitis scoring analysis showed marked differences between mice receiving $\mathrm{CD} 19^{+} \mathrm{IgM}^{+}$cotransfers versus mice receiving splenocytes only or the removal of $\operatorname{IgM}^{+}$cells prior to cotransfer, with the differences being found by skewing the islet scores toward a 1 in the dual-sorted cotransfer recipients as compared with controls (Figure 4B). Furthermore, the B cell repertoire found within the pancreatic lymph nodes of a representative NOD.scid recipient receiving CD19+ $\operatorname{IgM}^{+}$B cells was very similar to the repertoire of $C D 19^{+} \operatorname{IgM}^{\text {h }}$ cells from the NOD donors, with a majority of cells belonging to either the MZ B cell pool or MZ precursors (Figure 4C). Immunofluorescent staining of pancreatic sections showed heightened levels of trafficked B cells within the islets of mice receiving $\mathrm{CD} 9^{+} \operatorname{IgM}^{+}$cotransfers as compared with controls. When comparing prediabetic mice receiving splenocytes only (Figure 5A) as compared with $\mathrm{CD}^{+}{ }^{+} \mathrm{IgM}^{+}$cotransfer recipients (Figure 5B) on day 20 after adoptive transfer, a greater number of $\mathrm{B}$ cells can be observed, with more $\beta$ cells being stained positive for the presence of insulin. Most strikingly when comparing representative islets at the time of euthanasia, the cotransfer recipient continued to have residual $\beta$ cell function, the presence of a few healthy insulin-producing islets, and trafficked B cells even 60 days after adoptive transfer (Figure 5D), while the matched splenocytes-only NOD.scid recipient control who developed diabetes on day 32 after transfer had almost no detectable insulin-positive $\beta$ cells remaining (Figure $5 \mathrm{C}$ ).

The $\mathrm{CD}_{19^{+}} \mathrm{IgM} \mathrm{M}^{+}$cells are still able to delay diabetes onset following depletion of Tregs. We next determined if cotransfer experiments of MHC-compatible splenocytes from NOD diabetic donors and CD19 ${ }^{+} \operatorname{IgM}^{+}$ cells from 6-week-old NOD donors were capable of inducing Treg expansion and possibly affecting diabetes onset through Tregs. We performed flow cytometry analyses to look for the presence of $\mathrm{CD} 3^{+} \mathrm{C}$ $\mathrm{D}^{+} \mathrm{CD} 25^{+} \mathrm{FoxP}^{+}$natural and inducible Tregs (Figure 6, A and B) and found no significant differences in terms of the total number of Tregs found between any of the treatment groups (Figure 6B). The effect Tregs may have on the ability of the $\mathrm{CD} 19^{+} \mathrm{IgM}^{+}$cotransfers to affect diabetes progression was assessed through Treg depletion experiments in which the diabetic splenocyte pool was depleted of CD25+ Tregs prior to adoptive transfer into NOD.scid recipients and also in the $\mathrm{CD}^{1} 9^{+} \mathrm{IgM}^{+}$cotransfers. Noticeably, $\mathrm{CD}_{19}{ }^{+} \mathrm{IgM}^{+}$cells can still delay diabetes onset in the NOD.scid recipients, even in the absence of Tregs (Figure $6 \mathrm{C} ; P<0.0001$ ). These findings reinforce the notion that the $\mathrm{CD} 19^{+} \mathrm{IgM}^{+}$cotransfers exhibit their protective effect on diabetes development independently from Tregs.

$I L-10$ secretion is critical for diabetes protection conferred by $C D 19^{+}$cells. Regulatory B cells have several mechanisms by which they can suppress immune responses, with the best characterized being production of IL-10 $(37,44,45)$. While peripheral blood serum showed no circulating IL-10 (Supplemental Figure 1D), it was important to establish whether or not IL-10 is associated with the protective effect of our cotransfer model. Therefore, we performed cotransfer experiments in the presence of either an anti-IL-10 neutralizing $\mathrm{mAb}$ or an IgG isotype-matched antibody and determined changes in diabetes development following injection of $\mathrm{CD}_{1} 9^{+}$cells harvested from 6-week-old NOD female donors (Figure 7A). Neutralization of secreted IL-10 using an IL-10 mAb effectively abrogated the protective effect of the CD19+ cells. In contrast, recipients of $\mathrm{CD} 9^{+}$cotransfers (namely NOD.scid mice that received an isotype-matched antibody) developed a delayed disease onset $(P=0.0005$, when comparing NOD.scid cotransfer recipients receiving either IL-10 mAb or IgG isotype-matched antibody injections without B cell cotransfer). Serum collected at the time of endpoint euthanasia verified that there was no circulating IL-10 in NOD.scid recipients receiving either the anti-IL-10 neutralizing $\mathrm{mAb}$ or IgG Isotype-matched control antibody. We ultimately sought to further characterize the level of residual IL-10 by determining the percentage of CD $19^{+} \operatorname{IgM} \mathrm{IL}^{+}-10^{+} \mathrm{B}$ cells in the spleen of NOD.scid recipients and found that these cotransfer recipients, even at the end of the study, had an increased number of IL-10+ B cells as compared with NOD.scid mice injected with splenocyte only (Figure 7B). These data suggest that IL-10 plays a significant role in the protective effect conferred by the $\mathrm{CD} 19^{+} \mathrm{IgM}^{+}$cell cotransfer experiments.

Previously published observations have shown that IL-5, in combination with CD40 receptor activation by its ligand CD40 ligand (CD40L), results in the expansion of regulatory B cells, as well as IL-10 production (46). However, the effect of IL-5 has yet to be analyzed in the context of T1D. In order to determine if stimulating IL-10 production by the B cells prior to transfer would enhance their regulatory 

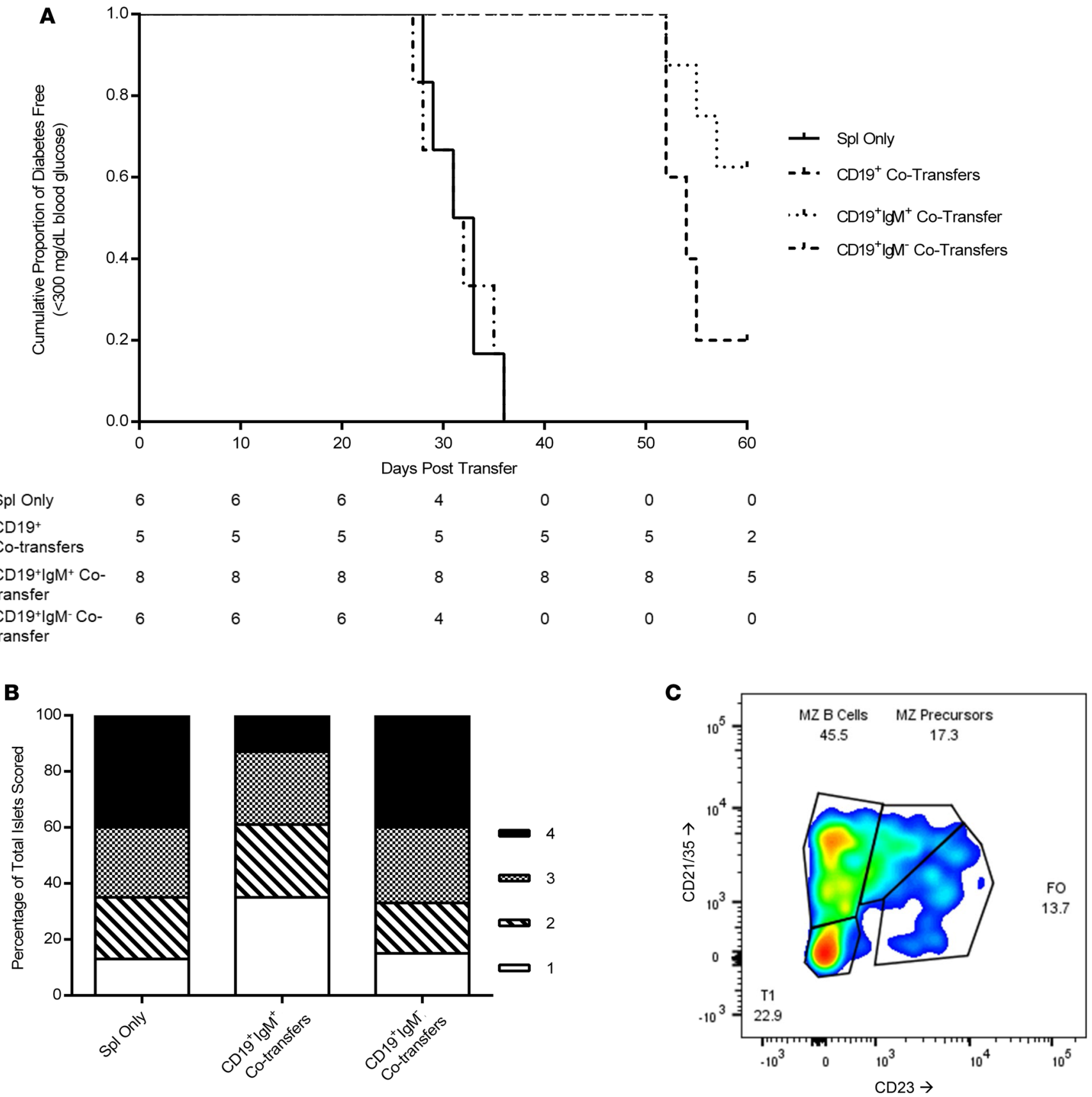

Figure 4. Dual-sorting B cells to purify $\mathrm{CD} 19^{+} \mathrm{IgM}^{+}$leads to increased protection over CD19+ single sorting, but removal of lgM+ cells inhibits the protective effect of $\mathrm{CD}_{19}{ }^{+}$cell cotransfers. (A) Survival curve for group comparison between female NOD.scid mice receiving diabetic splenocytes ( $n=6$, solid line), splenocytes plus CD19+ cells from 6-week-old NOD donors ( $n=5$, dashed line), splenocytes plus CD19+lgM+ dual-sorted cells from 6-week-old NOD donors ( $n=8$, dotted line), and splenocytes plus CD19+|gM- dual-sorted cells from 6-week-old NOD donors ( $n=6$, dot-dashed line). The population values represent number of diabetes-free mice at each time-point. (B) Insulitis scoring results from pancreatic sections stained with H\&E of NOD.scid recipients that received either diabetic splenocytes ( $n=6$ mice), splenocytes cotransferred with bead-purified CD19+lgM+ cells from 6-week-old NOD donors ( $n=8$ mice), or splenocytes cotransferred with CD19+IgM- cells purified from 6 -week-old NOD female donors ( $n=6$ mice). Islets were individually scored on a 1-4 scale of increasing insulitis severity, and the percentage of each score as a part of the whole was graphically represented. (C) B cell repertoire of CD19+lgM+ cells taken from the pancreatic lymph nodes of a NOD.scid recipient receiving dual-sorted $\mathrm{CD}^{1} 9^{+} \mathrm{IgM}^{+}$cells. Cells initially gated on $\mathrm{CD} 19^{+} \mathrm{IgM}^{+}$and then subgated by CD21/35 and CD23.

ability and IL-10 secretory capabilities, we used magnetic bead-separated CD19+ B cells harvested from 6-week-old NOD mice and cultured them in the presence of CD40L plus IL-4, IL-5, a combination of both IL-4 and IL-5, or no cytokine. Our results demonstrate that CD19+ B cells from NOD mice rapidly proliferate in the presence of IL-5 over that of treatment with no additional cytokines or IL-4, as seen by ${ }^{3} \mathrm{H}$ thymidine uptake in dividing cells $(P=0.003)$ (Figure $\left.7 \mathrm{C}\right)$. This proliferation is dampened in the 

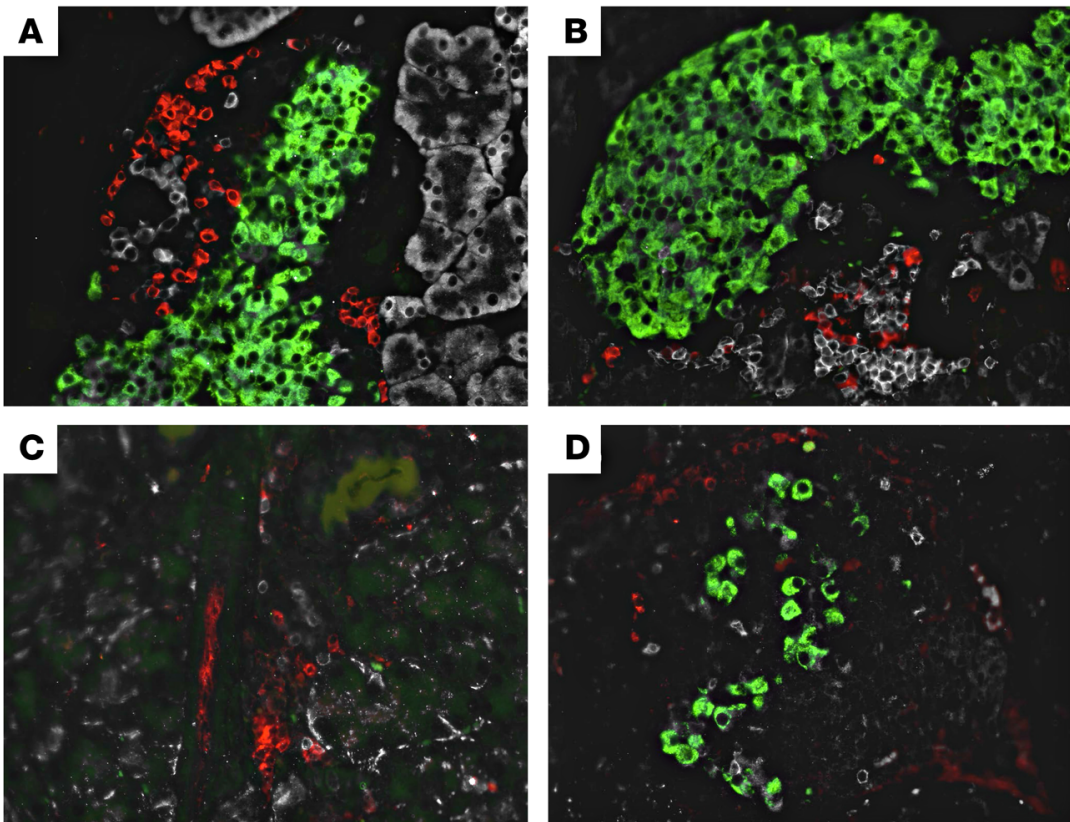

Figure 5. B cells and T cells traffic to the islets during insulitis, and more $\beta$ cells are conserved in NOD.scid mice after receiving $\mathrm{CD}^{+} \mathbf{I}^{+} \mathrm{IgM} \mathbf{M}^{+}$cotransfers. (A) Immunofluorescent image of pancreatic islet (green) stained for $\mathrm{CD}^{+} \mathrm{T}$ cells (red) and $\mathrm{B} 22 \mathrm{O}^{+} \mathrm{B}$ cells (white) taken from a prediabetic NOD.scid recipient receiving only diabetic splenocytes on day 20 after adoptive transfer. (B) Immunofluorescent image from a prediabetic NOD.scid recipient receiving diabetic splenocytes plus CD19+| IgM+ dual-sorted cells on day 20 after adoptive transfer. (C) Immunofluorescent image from a new-onset diabetic NOD.scid recipient receiving only diabetic splenocytes on day 32 after adoptive transfer. (D) Immunofluorescent image from a nondiabetic NOD.scid recipient receiving diabetic splenocytes plus CD19+1gM+ dual-sorted cells on day 60 after adoptive transfer. Original magnification, 40x.

presence of IL-4, which is known to stimulate FO B cell maturation over that of MZ B cells (47-49). CD $19^{+} \mathrm{B}$ cells from NOD mice also showed vastly increased secretion of IL-10 in vitro when stimulated with IL-5 whether the B cell pool was collected from 6-week-old female NOD mice or older diabetes-prone 12-week-old NOD female donors (Figure 7D), although levels of IL-10 secretion are higher in young 6-week-old NOD mice $(P=0.04)$.

We then evaluated whether the IL-10 (likely being secreted by IL-5 stimulated CD19+ cells) was capable of delaying or preventing diabetes onset in NOD.scid recipients after adoptive transfer of diabetic splenocytes. Cotransfer experiments using IL-5-stimulated CD19+ cells induced a similar protective effect on diabetes pathogenesis in recipient mice, with $20 \%$ of the NOD.scid recipients maintaining normal levels of blood glucose even 60 days after adoptive transfer (Figure 8A). Notably, these results were highly significant $(P=0.0006)$, and even with a final boost at day 12 after adoptive transfer, some NOD.scid recipients were presenting with protection against disease onset. We also were able to detect increased IL-10 levels in the serum of IL-5-stimulated CD19+ cotransfer recipients at endpoint as compared with diabetic controls up to 2 months after adoptive transfer (Figure $8 \mathrm{~B} ; P=0.01$ ). We then attempted to determine if the spike in detectable IL-10 was due to upregulation in the number of $\mathrm{CD}^{+} \mathrm{CD} 4{ }^{+} \mathrm{CD} 25^{+} \mathrm{FoxP} 3^{+}$Tregs that can be activated to proliferate in the presence of regulatory $\mathrm{B}$ cells. Nonetheless, flow cytometric analysis showed no changes in the Treg numbers in any of the treatment groups, supporting our hypothesis that the IL-5-stimulated CD19+ cells are the source of the endogenous detectable IL-10 level (Figure 8C).

Histologic analysis in mice receiving IL-5-stimulated CD19+ cotransfers had less insulitis as compared with NOD.scid recipients receiving diabetic splenocytes only (Figure 9, A-C). When scored, the IL-5-stimulated CD19+ ${ }^{+}$cotransfer recipient NOD.scid mice had more islets scoring with a 1 , and fewer with a 4 , as compared with age-matched control NOD.scid recipients (Figure 9C). Finally, immunofluorescence studies showed trafficking of B cells to the pancreatic islets - even on day 60 after adoptive transfer - and the presence of residual insulin-positive $\beta$ cells in the IL-5-stimulated CD19+ ${ }^{+}$cotransfer cohort (Figure 9E), as compared with recipients of splenocytes only (Figure 9D). 
A
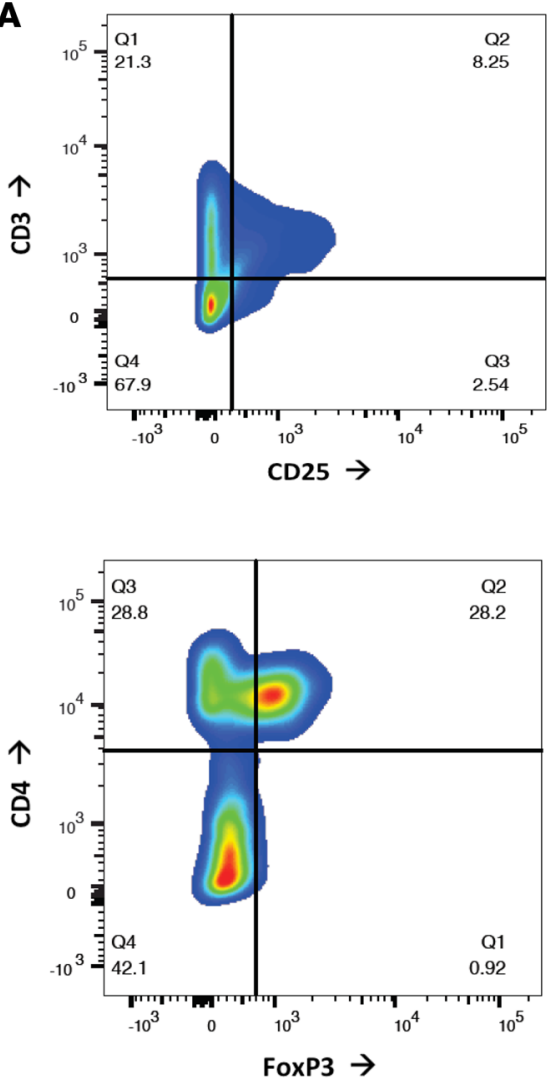

B

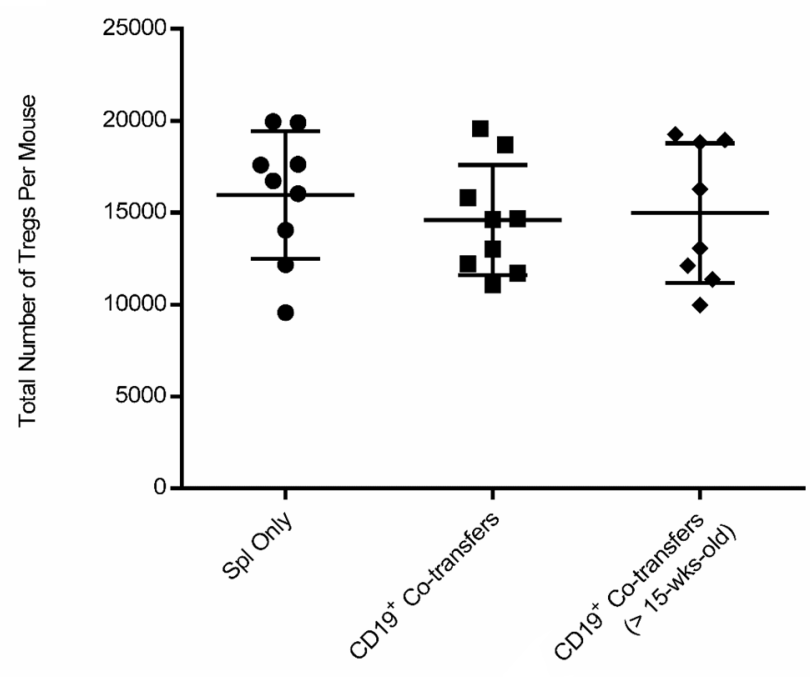

C

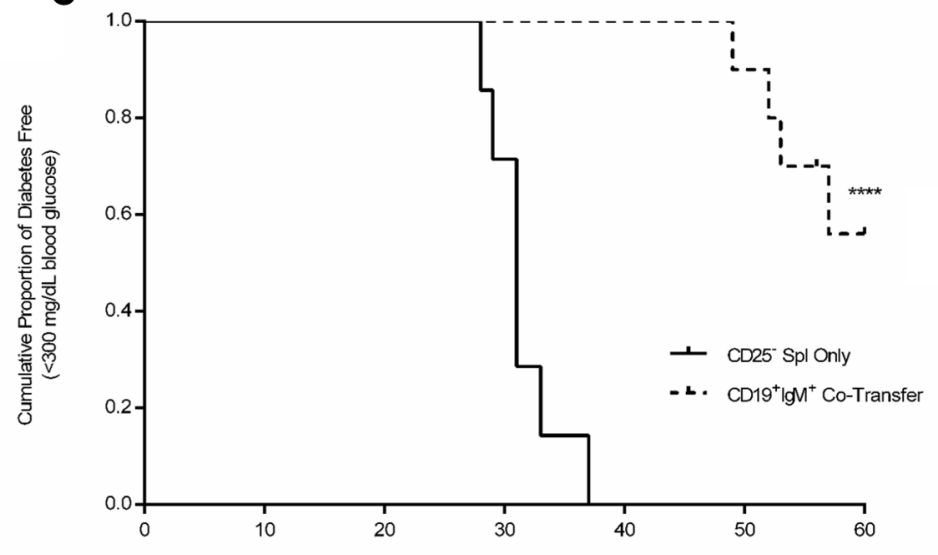

$\begin{array}{lccccccc}\text { CD25- Spl Only } & 7 & 7 & 7 & 3 & 0 & 0 & 0 \\ \begin{array}{l}\text { CD19+|gM+ Co- } \\ \text { Transfer }\end{array} & 10 & 10 & 10 & 10 & 10 & 9 & 6\end{array}$

Figure 6. Delay in onset by CD19+IgM+ cotransfers is independent of Tregs. (A) Tregs were analyzed from splenocytes of NOD.scid recipients. Representative staining protocol for analyzing Tregs showing primary gating for $\mathrm{CD} 3^{+} \mathrm{CD} 25^{+}$cells and gating on the $\mathrm{CD} 4^{+} \mathrm{FoxP3} 3^{+}$population within the $\mathrm{CD} 3^{+} \mathrm{CD} 25^{+}$gate. (B) $\mathrm{CD}^{+} \mathrm{CD}^{+} \mathrm{CD} 25^{+} \mathrm{FoxP3}^{+}$Tregs were quantified from 26 NOD.scid recipients receiving 1 of 3 stated treatment options. Total splenocytes were calculated using the percentage subgroup populations and nonsignificant $P$ values calculated as a nonparametric $t$ test with Welch's correction. (C) Depletion of Tregs. Survival curve for group comparison between female NOD.scid mice receiving CD25- diabetic splenocytes ( $n=7$, solid line) and CD25- splenocytes plus CD19+lgM ${ }^{+}$dual-sorted cells from 6-week-old NOD donors ( $n=10$, dotted line). Results analyzed using the Mantel-Cox Log Rank test for survivability (*** $P<0.0001$ ). The population table represents number of diabetes-free mice at each time point.

\section{Discussion}

Accumulating evidence suggests that B cells play a role in the pathogenesis of autoimmune disorders including T1D (21). This autoimmune disease is characterized by the generation of autoantibodies against self-antigens $(50,51)$, and immunomodulation is a logical approach for effective therapy $(28,52-60)$. This is further supported by the early $\mu$-chain-KO mouse experiments whereby deletion of the $\mu$-chain in mice led to a lack of mature B cells in the periphery and impaired diabetes progression in NOD mice (22, 61-63). These $\mathrm{KO}$ experiments revealed the importance of $\mathrm{B}$ cells as antigen presenters. Our results suggest that a subset of B cells exhibiting a regulatory effect can traffic to the pancreas and may well play a pivotal role in delaying diabetes progression $(23,64)$.

Our results demonstrate that diabetes is significantly delayed in an adoptive transfer model following injections of MHC-compatible CD19+ cells harvested from young NOD female donors. Further separa-

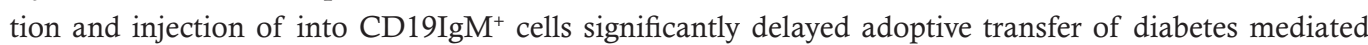
by diabetogenic $\mathrm{T}$ cells from NOD mice unlike the injection of $\mathrm{CD}_{1} 9^{+} \mathrm{IgM}^{-} \mathrm{B}$ cells. The protective effect 
B

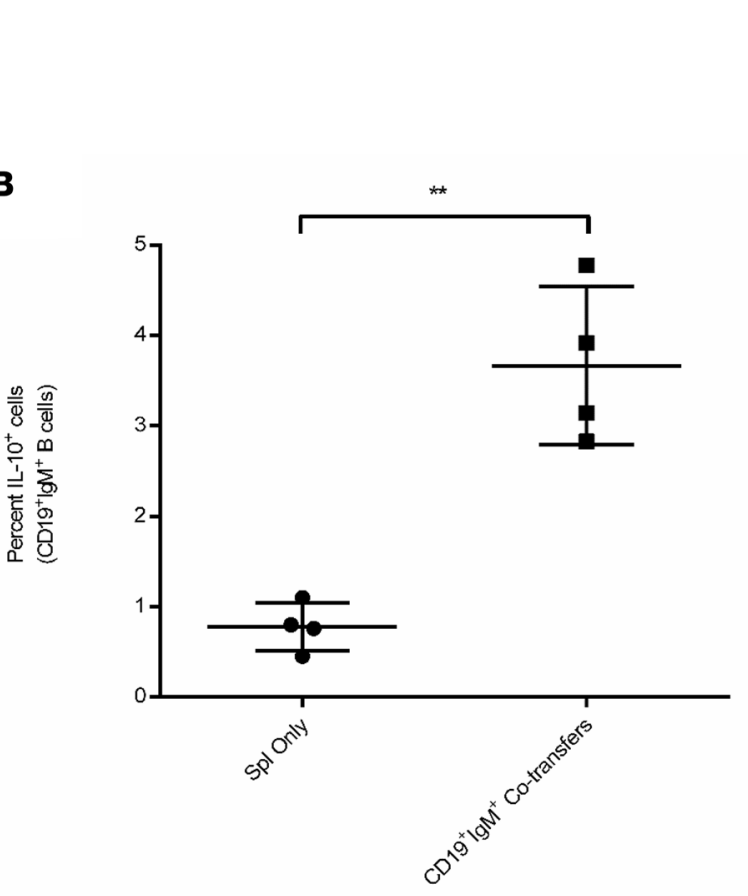

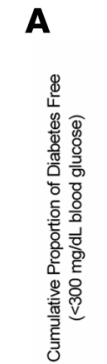

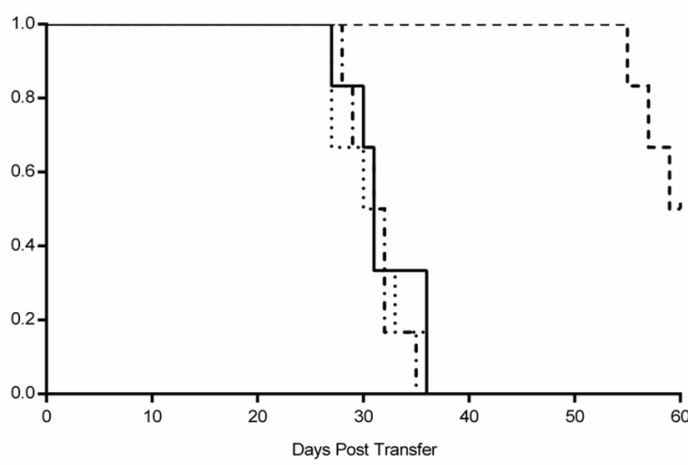

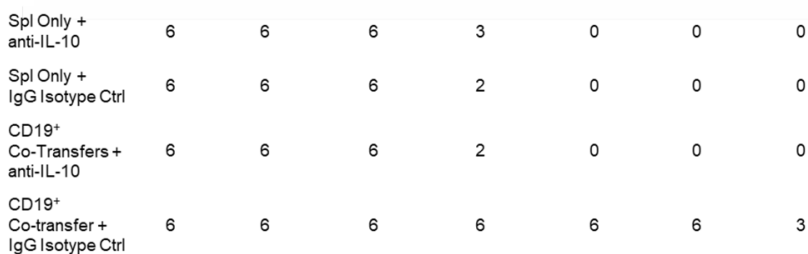

$$
\begin{aligned}
& \text {-- Spl Only + anti-IL-10 mAb } \\
& \text { - Spl Only + IgG Isotype Ctrl } \\
& \text { ‥ CD19 Co-Transfers + anti-IL-10 mAb } \\
& \text { - L. CD19+Co-Transfer + IgG Isotype Ctrl }
\end{aligned}
$$
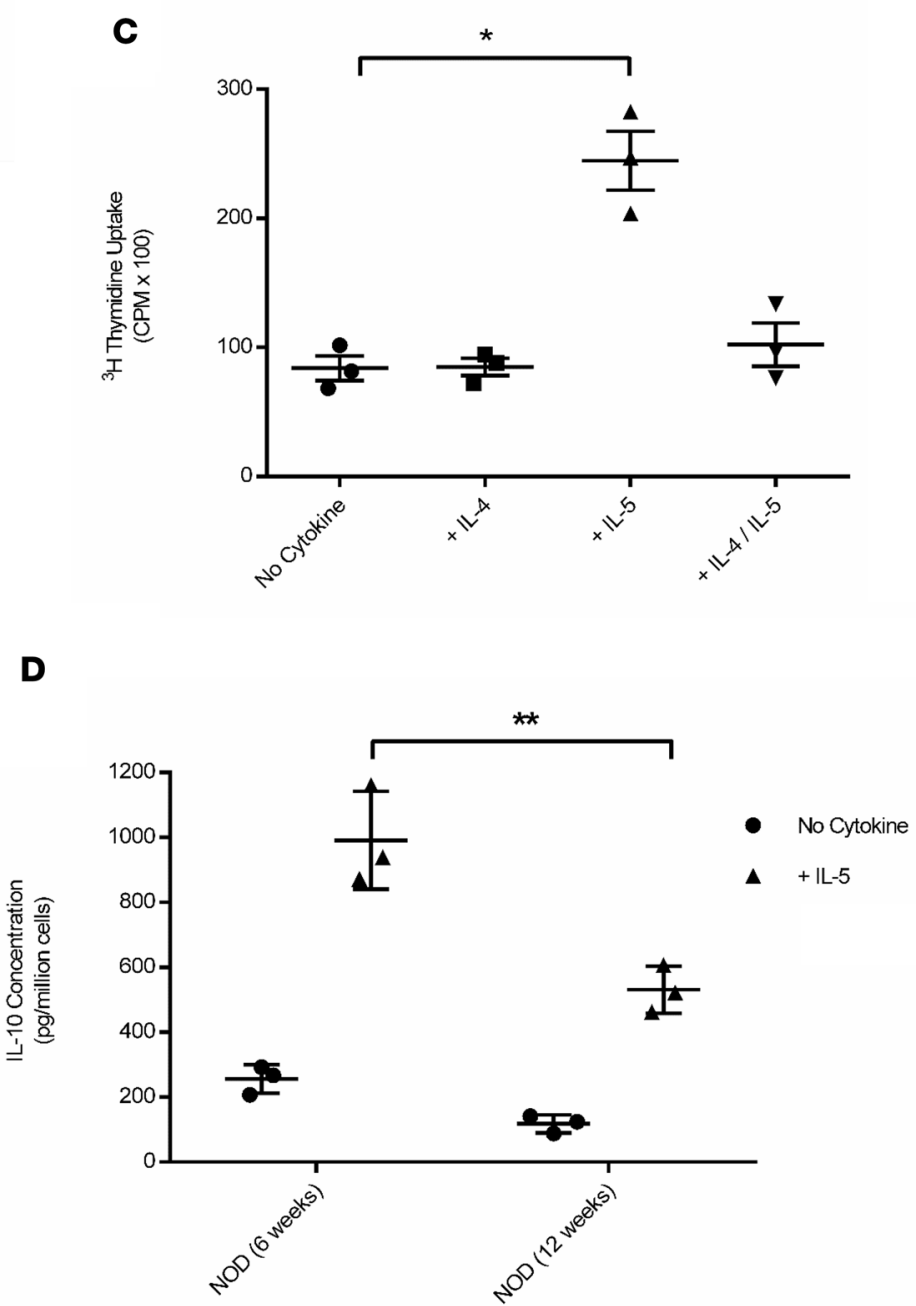

Figure 7. Importance of IL-10 secretion for protection and development of in vitro cultures of CD19+ cells with IL-5 inducing increased IL-10 secretion. (A) Survival curve for group comparison between female NOD.scid mice receiving diabetic splenocytes plus anti-IL-10 mAb ( $n=6$, dot-dashed line), splenocytes plus IgG Isotype Control Ab ( $n=6$, solid line), splenocytes plus CD19+ cells from 6-week-old NOD donors and anti-IL-10 mAb ( $n=6$, dotted line), and splenocytes plus $\mathrm{CD} 19^{+}$cells from 6-week-old NOD donors and IgG isotype control Ab ( $n=6$, dashed line). The population values represent number of diabetes-free mice at each time point. (B) Percentage of total splenic CD19+IgM+IL-10+ B cells analyzed by flow cytometry from NOD.scid recipients receiving either diabetic splenocytes or splenocytes plus $\mathrm{CD} 19^{+} \mid \mathrm{gM}^{+}$cells. (C) Proliferation assay using ${ }^{3} \mathrm{H}$ thymidine incorporation of CD19+ ${ }^{+}$cells cocultured with 3 T3 fibroblasts expressing CD4OL and in the presence of no additional cytokines, IL-4, IL-5, or a combination of IL-4 and IL-5. (D) After 6 days in culture, supernatants from 6-week-old or 12-week-old donor mice were collected and screened by ELISA for concentration of secreted IL-10. Secreted IL-10 was measured in pictograms per million cells, and all conditions were plated in triplicate using pooled splenocytes from 6-week-old or 12-week-old NOD female donors. ${ }^{*} P=0.008$ and ${ }^{*} P=0.024$ were analyzed using $t$ tests of experiments performed in triplicate.

conferred by these cells appears to be age specific in that $\mathrm{CD} 19^{+}$cells from 6-week-old prediabetic NOD mice may well have regulatory components acting to block diabetes development and insulitis, unlike $\mathrm{CD} 19^{+}$cells from $>15$-week-old NOD mice. Of note, low-dose anti-thymocyte globulin/granulocyte CSF (ATG/G-CSF) treatment in newly diagnosed T1D patients was associated with preservation of C-peptide and significantly increased numbers of $\mathrm{CD} 19^{+}$cells (65). 
A
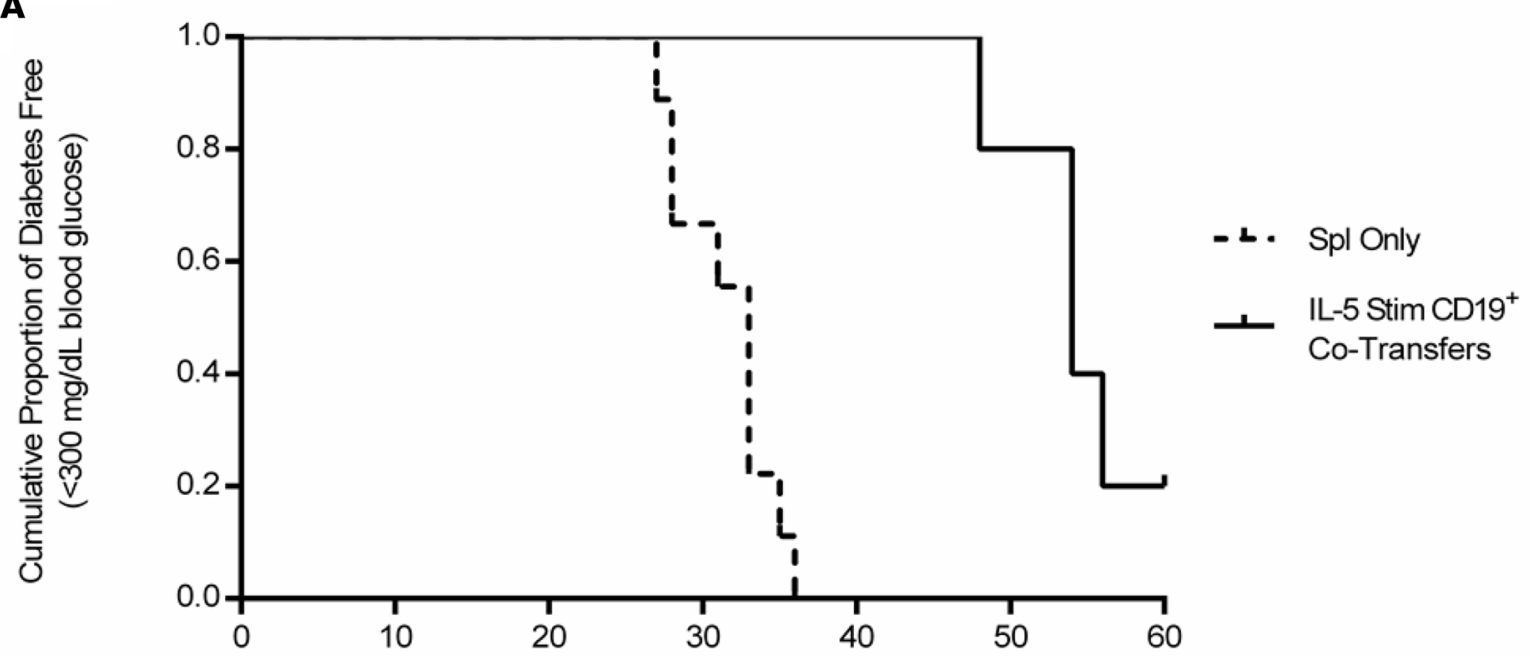

Days Post Transfer

\begin{tabular}{|c|c|c|c|c|c|c|}
\hline Spl Only & 9 & 9 & 9 & 5 & 0 & 0 \\
\hline $\begin{array}{l}\text { IL-5 Stim } \\
\text { CD19+ Cells }\end{array}$ & 5 & 5 & 5 & 5 & 5 & 4 \\
\hline
\end{tabular}

B

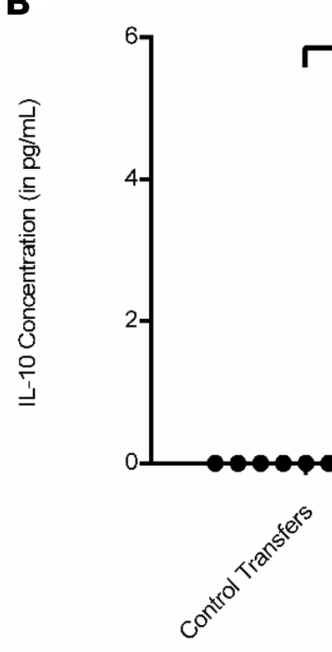

$\star * *$

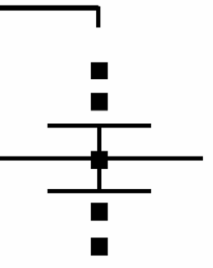

C

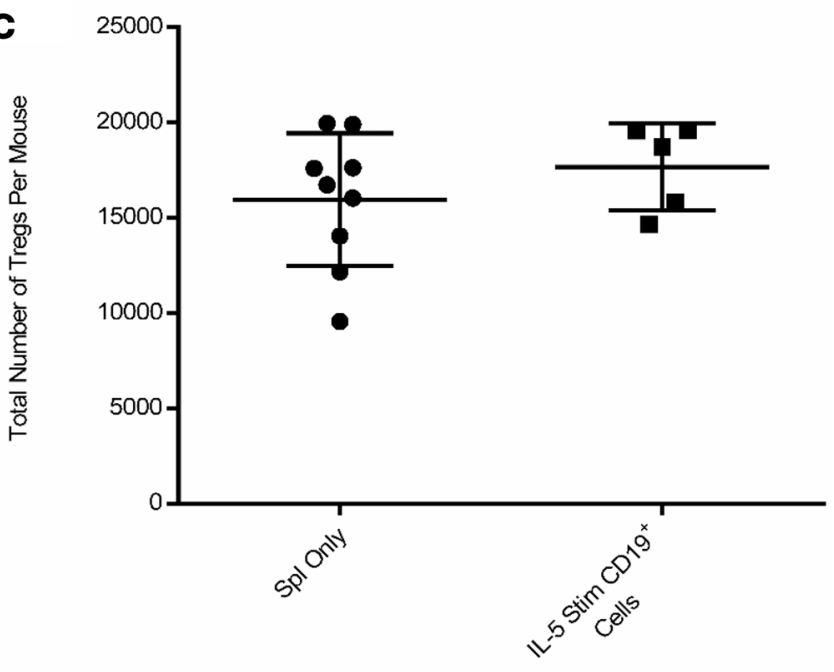

Figure 8. Ex vivo IL-5-stimulated CD19+ cells result in increased IL-10 level and delay in diabetes onset following adoptive transfer into NOD.scid recipients. (A) Survival curve for group comparison between female NOD.scid mice receiving diabetic splenocytes $(n=9$, dashed line) or splenocytes plus IL-5-stimulated CD19+ cells from 6-week-old NOD donors ( $n=5$, solid line). Results analyzed using the Mantel-Cox Log Rank test for survivability $(P=0.0006)$. The population values represent number of diabetes-free mice at each time point. (B) Serum was collected during endpoint analysis and measured by ELISA for the presence of secreted IL-10 $\left({ }^{* * *} P=0.015\right)$. Comparisons between mice receiving either diabetic splenocytes only or splenocytes plus IL-5-stimulated CD19+ cells from 6-week-old NOD donors. (C) CD3+CD4+CD25+FoxP3 ${ }^{+}$Tregs were analyzed in NOD. scid recipients ( $n=9$ in Spl Only and $n=5$ in IL-5 Stim CD19+ (ells group), with total Tregs calculated using the percentage subgroup populations with nonsignificant $P$ values calculated using a nonparametric $t$ test with Welch's correlation.

Traditionally, it has been believed that the main source of IL-10 during regulation came from Tregs activated to ablate the immune response $(1,66-69)$. However, we provide evidence that IL-10-secreting $\mathrm{B}$ cells result in a significant delay in diabetes onset that was achieved independently of Tregs (Figure 6C). Treatment with a neutralizing IL-10 mAb ablated the protective effect of $\mathrm{CD}^{+} 9^{+}$cells, whereas 

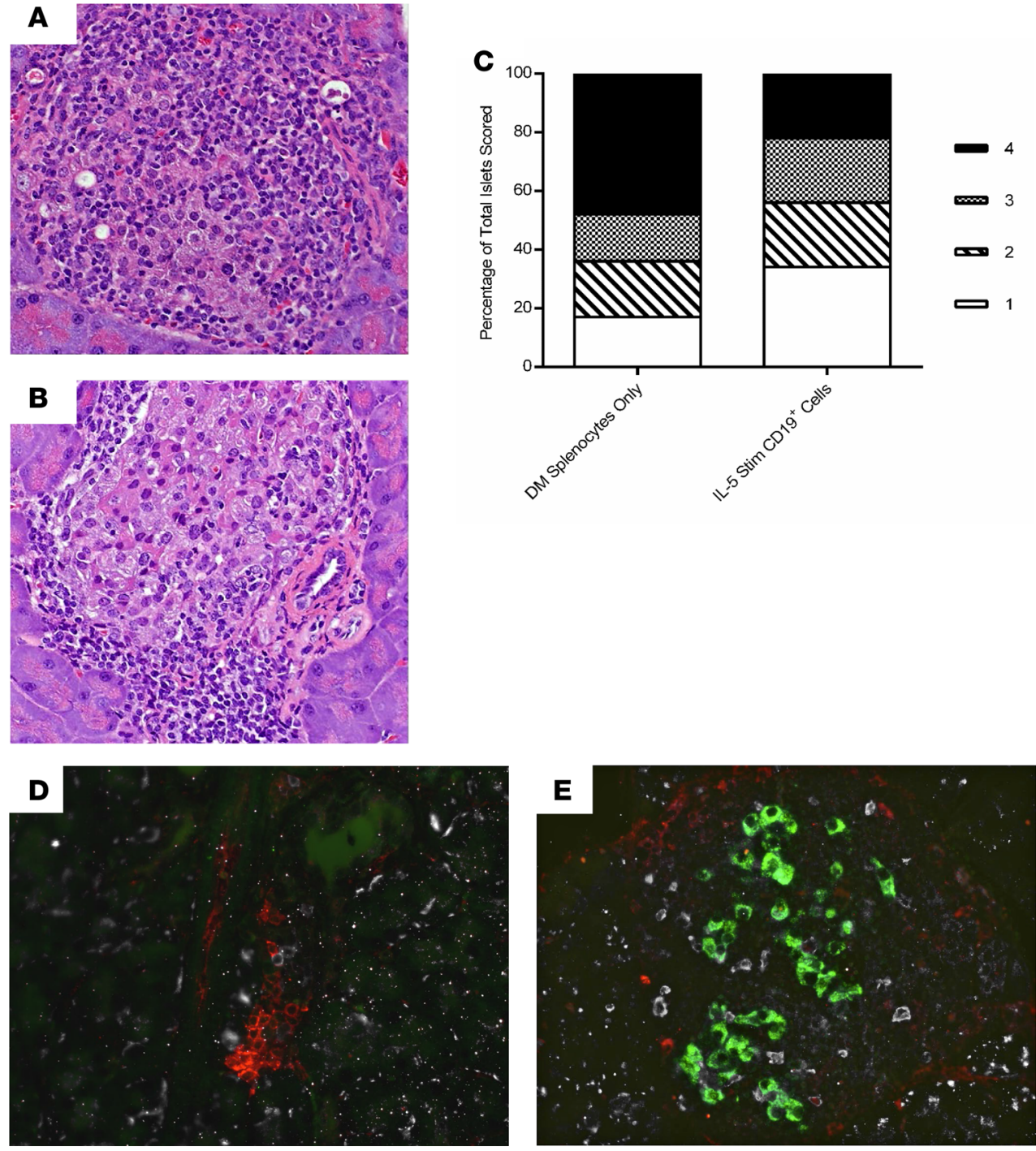

Figure 9. IL-5-stimulated CD19+ cotransfer recipients have less insulitis and a higher numbers of $B$ cells within their islets, as well as increased levels of residual insulin production within $\beta$ cells. (A) Representative H\&E staining of an islet from a NOD.scid recipient receiving only diabetic splenocytes. (B) Staining of a representative islet from a 60-day posttransfer nondiabetic NOD.scid mouse after receiving splenocytes from IL-5-stimulated CD19+ cells. (C) Pancreatic sections scored for levels of insulitis and graphically represented as a percentage of total isles scored. Islets scoring 1 resulted in $P=0.0002$, and islets scoring a 4 resulted in $P<0.0001$ when analyzed using a $2 \times 2$ contingency table and $\chi^{2}$ analysis. (D) Immunofluorescent image of pancreatic islet (green) stained for $\mathrm{CD}^{+} \mathrm{T}$ cells (red) and B220+ $\mathrm{B}$ cells (white) obtained from a new-onset diabetic NOD.scid recipient receiving diabetic splenocytes on day 30 after adoptive transfer. (E) Immunofluorescent image from a prediabetic NOD.scid recipient receiving diabetic splenocytes plus IL-5-stimulated CD19+ cells on day 60 after adoptive transfer. Original magnification $40 \times$.

increasing the production of IL-10 by CD19+ $\mathrm{B}$ cells with IL-5 resulted in a delay in diabetes onset, as well as a systemic increase in IL-10 serum level.

Several stimuli increase production of IL-10 by B lymphocytes, including IL-21, B cell-activating factor (BAFF), a proliferating inducing ligand (APRIL), Cytosine-phosphate-guanine oligodeoxynucleotides (CpG ODN), LPS, and the combination of CD40 ligation and IL-5 (46, 70-73). Of these, the CD40L-specific nature of IL-5-induced IL-10 production leads us to believe that this may, in fact, be a superior route for inducing IL-10 regulatory B cell proliferation ex vivo. Since CD40L is upregulated on activated Th cells, this requirement would be expected to limit the IL-5-induced IL-10 production by B cells only to environments in which activated $\mathrm{T}$ cells were present, such as inflamed pancreatic islets. Remarkably, our results suggest that IL-5 has a strong stimulating activity on CD19+ B cells in the NOD strain (Figures 7, C and D) (46). We found that NOD B cells are capable of secreting abundant amounts of IL-10 upon stimulation with 
IL-5, and the potential implications of using IL-5 as a regulatory B cell-stimulating molecule for protection against onset or continued progression of T1D is intriguing. It will be interesting to test whether or not B cells from patients with T1D produce normal levels of IL-10 following various types of stimulation. Notably, in humans, it has been shown that circulating levels of IL-5 and IL-10 increase after pharmacologic treatment with the combination antiepileptic drugs carbamazepine and valproic acid $(74,75)$. The chemotherapeutic drug Bendamustine, which is used to treat some B cell malignancies, has also been shown to induce IL-10 production by human B lymphocytes (76). Our results demonstrated that the ability of 6-week-old purified $\mathrm{CD} 19^{+}$cells to significantly delay disease progression was not dependent on in vitro activation by cytokines prior to adoptive transfer as seen in other studies $(27,28,47,70,77)$. We also found that the unstimulated $\mathrm{B}$ cell transfer yielded no evidence of expansion of Tregs (Figure 6B) or loss of M1 macrophages (Supplemental Figure 1B), suggesting that B cells might be the primary drivers of protection in a more localized fashion.

We found NOD.scid recipients receiving MHC-compatible splenocytes and CD19+ ${ }^{+}$cells from a 6-weekold NOD donor had no measurable IL-1 $\beta$ level compared with any other transfer group (Figure 3F). Production of the proinflammatory cytokine IL-1 $\beta$ is mainly attributed to activated monocytes and macrophages, but the nature of a direct interaction of these cells with the Bregs remains to be elucidated (78-80). It has been observed, however, that the induction of IL-1 $\beta$ and IL-1ra was severely inhibited in the presence of IL-10 in LPS-induced monocytes and that IL-10 may act on inflammatory cells to inhibit production of proinflammatory transcription factors $(81,82)$.

In conclusion, our observations suggest that there is a subpopulation of $\mathrm{CD}^{+} 9^{+} \mathrm{IgM}^{+}$cells in the B cell compartment of young prediabetic NOD mice that exhibits a robust suppressive effect on diabetes pathogenesis. These results provide evidence for a suppressive function of $\mathrm{CD}_{1}{ }^{+} \mathrm{IgM}^{+}$cells in autoimmune diabetes that could be a cellular target for immunotherapy.

\section{Methods}

Mouse Models. NOD (catalog 00196), NOD.scid (catalog 001303), C57BL/6 (catalog 000664), and Balb/c (catalog 000651) mice were purchased from the Jackson Laboratory or bred in-house in specific pathogen free cages using breeding pairs originally purchased from the Jackson Laboratory. Some diabetic NOD female cell donors were provided from the laboratories of Matthew Bettini and Maria Bettini (Baylor College of Medicine). Six-week-old NOD.scid (Cat.\#001303) female mice containing gene mutations resulting in an inability to generate mature $\mathrm{T}$ cells and $\mathrm{B}$ cells, thereby having no adaptive immune system, were used as immunocompromised recipients for all adoptive transfer experiments described below.

Monitoring for diabetes. All aging NOD donor mice and NOD.scid recipients receiving adoptive transfers of splenocytes were monitored biweekly (starting 1 week after adoptive transfer or upon reaching 10 weeks of age) for increases in blood glucose levels. A single drop of blood was collected from the tail through a small nick at the distal end and collected by capillary action into an Accu-Chek Aviva Blood Glucose Monitor. Mice were considered diabetic after 2 consecutive blood glucose measurements above $300 \mathrm{mg} / \mathrm{dl}$.

Cell harvest and preparation. Spleens were harvested from different strains of euthanized female mice at 6 weeks of age or $>15$ weeks of age. Single cell suspensions were prepared using cell strainers and ACKS lysis buffer to remove RBCs and were then suspended in PBS to be counted before being placed in culture or undergoing immediate analysis by flow cytometry. Cells being collected for adoptive transfer are described below.

Adoptive transfer experiments. NOD.scid female mice 6 weeks of age (the Jackson Laboratory) were used as splenocyte recipients across all treatment groups. Experiments were performed in triplicate using 3-4 mice per group before pooling similar experiments in order to ensure reproducibility and technical efficiency. To induce diabetes, NOD.scid females were i.v. injected with $5 \times 10^{6}$ splenocytes from diabetic female NOD mice through a tail vein injection $(15,32,33)$. For the cotransfer experiments, NOD.scid females received $5 \times 10^{6}$ splenocytes from diabetic NOD female donor mice in addition to $5 \times 10^{6} \mathrm{CD} 19^{+}$cells harvested from 6-week-old or $>15$-week-old NOD female donors. Donor CD19+ cells were purified using the Miltenyi CD19+ microbeads system in MACS LS magnetic sorting columns (Miltenyi Biotec, catalog 130-052-201). Dual-selected CD19+ cells were purified using a 2-step approach. Splenocytes were obtained from 6-week-old NOD female donors and selected using the same $\mathrm{CD} 19^{+}$microbeads; they were then washed to remove any remaining $\mathrm{CD} 19^{+}$antibodies or microbeads, and the $\mathrm{CD} 19^{+}$cell fraction was run through a second MACS LS sorting column using Miltenyi $\operatorname{IgM}^{+}$microbeads (catalog 130-047-301). For the Treg depletion experiments, splenocytes from the diabetic NOD donor were purified using the Miltenyi CD25 microbeads system (catalog 130-091-072), with the negative fraction being collected for adoptive transfer into NOD.scid recipients as described above. 
On day 6 after initial adoptive transfer injections, a second i.v. injection of freshly purified CD19+ cells obtained from the spleens of 6-week-old or $>15$-week-old NOD females was performed in cotransfer NOD.scid recipients using $5 \times 10^{6}$ cell concentration in sterile PBS. On day 12 after transfer, another boost of freshly purified splenic CD19+ cells was injected i.v. to maintain a larger B cell pool within the cotransfer recipient NOD.scid mice. NOD.scid recipients were followed for diabetes onset or until day 60 after transfer of diabetic splenocytes, and they were euthanized upon meeting either endpoint requirement.

Antibody administration for neutralizing experiments. Female NOD.scid recipients receiving cotransfers of $\mathrm{CD} 19^{+}$sorted cells and/or splenocytes from a diabetic NOD female donor also received i.p. injections of $100 \mu 1$ of either the BioLegend LEAF Purified anti-mouse IL-10 neutralizing mAb (catalog 504904) or the matching BioLegend LEAF Purified rat IgG2b, $\kappa$ isotype control antibody (catalog 400637). Injections were given i.p. on day 1 after adoptive transfer of diabetic splenocytes and then every 5 days for 40 days until either diabetes occurred or day 40 after adoptive transfer per previously described protocols provided by the manufacturer.

Tissue processing, histology, and insulitis scoring. After NOD.scid recipients developed diabetes, they were euthanized and the pancreas was collected and fixed in $10 \%$ formalin for future H\&E staining to determine cellular structures. Individual islets were scored across multiple sections for each mouse for the presence of infiltrating lymphocytes to determine the level of insulitis. Individual islets were given a score of 1-4 depending on the severity of islet infiltration according to established protocols (83): a score of 1 represented little or no insulitis, 2 represented mild insulitis covering less than $20 \%$ of the total islet, a score of 3 represented an islet with between $20 \%-50 \%$ moderate insulitis, and a score of 4 represented an islet with severe infiltration covering $>50 \%$ of the islet. All islets were scored on an Olympus light microscope, captured using Olympus cellSens software, and they were statistically analyzed in GraphPad Prism 6.0 using a $2 \times 2$ contingency table with $\chi^{2}$ analysis to determine differences between treatments and scoring patterns.

$I H C$. Paraffin sections were prepared as described previously (84). Sections were incubated with primary antisera including guinea pig anti-insulin (Dako), monoclonal mouse anti-CD3 (Abcam, catalog ab17143), and rat anti-mouse B220 (BD Biosciences, catalog 557390), followed by secondary antisera conjugated to Cy2/Cy3/Cy5 (Jackson ImmunoResearch) and DAPI (Molecular Probes), as previously described (85). Slides were blinded for imaging and qualitative analysis. All islets in 1 pancreas section were captured with a Zeiss AxioImager M1 (Carl Zeiss) and Volocity 6.1.1 software (PerkinElmer).

Flow cytometry. Cells collected either directly from spleens, pancreatic lymph nodes, or after undergoing $\mathrm{CD}_{1} 9^{+}$microbeads purification were placed into 96 -well plates (sterile flat-bottomed) at a preferred concentration of $5 \times 10^{5}$ cells per well. Cells were washed with FACS buffer (PBS, 10\% FCS [heat attenuated], and $0.5 \%$ sodium azide $\left.\left[\mathrm{NaN}_{3}\right]\right)$, nonspecific immunoglobulin binding was blocked with Fc-Block (BD Biosciences, catalog 553142), and cells were incubated with the corresponding fluorophore-conjugated antibodies (BD Bioscience) listed below. Cells were stained with one or more of the following antibodies: CD1d (catalog 562712), CD3 (catalog 553066), CD4 (catalog 562891), CD5 (catalog 565504), CD8 (catalog 562315), CD11c (catalog 562454), CD16/32 (catalog 558636), CD19 (catalog 562701), CD21/35 (catalog 558658), CD23 (catalog 562929), CD25 (catalog 564424), F4/80 (catalog 565613), FoxP3 (catalog 562466), IFN- $\gamma$ (catalog 562018), IgM (catalog 562565), IL-10 (catalog 554468), IL-17 (catalog 562542), or Mac-1 (catalog 562317). All flow antibodies were purchased from BD Biosciences.. After incubation with fluorescent antibodies, cells were washed and analyzed on either a BD Accuri C6 or BD LSR II flow cytometer. Propidium iodide staining was performed to exclude dead cells from subsequent analysis. All resulting data were analyzed using Tree Star FlowJo software.

ELISA. Serum from NOD.scid recipients and supernatant from cultured CD19+ cells were collected for cytokine analysis. Sandwich ELISAs were performed on these collected supernatants using the BD Bioscience kit for the following secreted cytokines: IL-1 $\beta$, IL-4, IL-10, IL-17, IFN- $\gamma$, and TNF- $\alpha$. All washes were done using tris-buffered saline (TBS) with $0.5 \%$ Tween 20 added (TBS-T). After addition of primary antibody and biotin-conjugated secondary antibody, plates were incubated with biotin-binding streptavidin-HRP to generate enzymatic activity for the blue colorization of the BD Bioscience Tetramethylbenzidine (TMB) substrate, followed by addition of a sulfuric acid Stop Solution to halt the enzymatic activity. Finally, plates were read on a Wallach 1420 plate reader for light absorbance and calculated against control protein concentrations to determine the light absorbance to protein concentration ratio. All data were analyzed and graphically represented using GraphPad Prism 6.0. 
$B$ cell culture conditions. CD19+ $\mathrm{B}$ cells harvested from the splenocytes of all mouse strains were positively selected by magnetic bead separation using MACS magnetic bead separation kits (catalog 130-052-201) with LS columns (Miltenyi Biotec). Purified CD19+ B cells were cultured in DMEM with L-glutamine media (Thermo Fisher Scientific, catalog 12430-062) with $10 \%$ FCS (heat attenuated at $65^{\circ} \mathrm{C}$; GE Healthcare, cata$\log \mathrm{SH} 3007103 \mathrm{HI}$ ), 0.5\% transferrin (Thermo Fisher Scientific, catalog 11107-018), 0.05\% insulin/transferrin (Thermo Fisher Scientific, catalog 41400-045), 1\% penicillin/streptomycin (Thermo Fisher Scientific, catalog 15140-122), and 1\% L-glutamine (Thermo Fisher Scientific, catalog 25030-081). Cells were incubated in 24-well plates under normal culture conditions for 5 days in the presence of irradiated (300Gy) murine CD40L-expressing NIH 3T3 fibroblasts generated in the laboratory of Kevin McDonagh, Vanderbilt University (Nashville, Tennessee, USA), and donated by David Fox, University of Michigan. Cells were plated at the concentration of $3 \times 10^{5} \mathrm{mCD} 40 \mathrm{~L}-3 \mathrm{~T} 3$ irradiated fibroblasts to $2 \times 10^{6} \mathrm{CD} 19^{+}$purified B cells. In addition, cells were stimulated with either $50 \mathrm{ng} / \mathrm{ml}$ of IL-4, IL-5, an equal ratio of IL-4 and IL-5 together, or no additional cytokines $(37,46)$. After 5 days, plates were removed from the incubator and centrifuged ( $300 \mathrm{~g}$ for 6 minutes at room temperature) before removal of supernatants for cytokine analysis. After removal of media, remaining cells were resuspended and collected for flow cytometric analysis. A subset of cells were set aside for analysis of cell proliferation after stimulation, where - upon being removed - media was immediately replaced with fresh B cell culture media containing $1 \mathrm{mCi} / \mathrm{ml}$ of ${ }^{3} \mathrm{H}$ thymidine, and cells were harvested 24 hours later to measure $\mathrm{B}$ cell proliferation by Thymidine incorporation. All data was graphically represented using GraphPad Prism.

Statistics. Kaplan-Meier plots were derived to estimate the cumulative risk of developing insulin-dependent diabetes. Kaplan-Meier plots were compared using the log-rank test and computed using an exact procedure and conducted as 1-sided tests (86). Survival curves were evaluated using the Mantel-Cox log-rank test for survivability between treatment groups.

Fisher's exact test and $\chi^{2}$ analyses were used to compare proportions and evaluate statistically significant associations between categorical variables. The Mann Whitney $U$ test for independent samples was used to compare continuous variables between 2 groups. Flow cytometry and serum ELISA comparative analyses of populations were performed using nonparametric 2-tailed $t$ tests with Welch's correction. ELISAs for IL-10 from in vitro IL-5 stimulation experiments were analyzed using nonparametric $t$ tests with Welch's correction. All statistical analyses were performed using GraphPad Prism 6.0. $P<0.05$ was considered statistically significant.

Study approval. All protocols involving mice were approved by the Animal Care Safety Review boards at both University of Michigan and Baylor College of Medicine.

\section{Author contributions}

ADV performed all adoptive transfer experiments and the majority of endpoint analyses. ADV wrote the manuscript with the help of MP, RG, and SKL. MAC and SLP assisted in many of the adoptive transfer experiments and performed statistical analyses, while ARC performed the immunofluorescence staining. SKL performed adoptive transfer experiments with ADV, performed some flow analysis, advised on roles of cell populations, and helped write the manuscript and contribute funding. MP oversaw all aspects of experimental design, data analysis, literature research, and manuscript writing and contributed the bulk of funding to this project.

\section{Acknowledgments}

This work was supported by the McNair Medical Institute at The Robert and Janice McNair Foundation, by NIH T32 Training grant (T32AI007413), and the Michigan Diabetes Research Training Center (MDRTC) funded by NIH grant 5P60-DK020572. A subset of NOD female diabetic donors and older $\mathrm{CD} 9^{+}$cell donors were donated from the laboratories of Matthew L. Bettini and Maria Bettini. Figure organization and presentation was designed by Richard Grubola of Market by Design (Detroit, Michingan, USA). We thank Ivan Maillard for helpful discussions and Emil R. Unanue and Jonathan M. Levitt for critical reading of the manuscript. Preliminary data relative to this work was presented at the 79th Scientific Sessions of the American Diabetes Association (Orlando, Florida, USA; June 2018).

Address correspondence to: Massimo Pietropaolo, Diabetes Research Center, Alkek Building for Biomedical Research, R609, Baylor College of Medicine, 1 Baylor Plaza, Houston, Texas, USA. Phone: 713.798.5988; Email: Massimo.Pietropaolo@bcm.edu. 
1. Shevach EM. Mechanisms of foxp3+ T regulatory cell-mediated suppression. Immunity. 2009;30(5):636-645.

2. D'Alise AM, et al. The defect in T-cell regulation in NOD mice is an effect on the T-cell effectors. Proc Natl Acad Sci USA. 2008;105(50):19857-19862.

3. Penaranda C, Tang Q, Bluestone JA. Anti-CD3 therapy promotes tolerance by selectively depleting pathogenic cells while preserving regulatory T cells. J Immunol. 2011;187(4):2015-2022.

4. Bluestone JA, Trotta E, Xu D. The therapeutic potential of regulatory T cells for the treatment of autoimmune disease. Expert Opin Ther Targets. 2015;19(8):1091-1103.

5. Bluestone JA, et al. Type 1 diabetes immunotherapy using polyclonal regulatory T cells. Sci Transl Med. 2015;7(315):315ra189.

6. Daifotis AG, Koenig S, Chatenoud L, Herold KC. Anti-CD3 clinical trials in type 1 diabetes mellitus. Clin Immunol. 2013;149(3):268-278.

7. Eisenbarth GS. Type I diabetes mellitus. A chronic autoimmune disease. N Engl J Med. 1986;314(21):1360-1368.

8. Atkinson MA, Eisenbarth GS, Michels AW. Type 1 diabetes. Lancet. 2014;383(9911):69-82.

9. Wong FS, Janeway CA. The role of CD4 vs. CD8 T cells in IDDM. J Autoimmun. 1999;13(3):290-295.

10. Crawford F, et al. Specificity and detection of insulin-reactive CD4+ T cells in type 1 diabetes in the nonobese diabetic (NOD) mouse. Proc Natl Acad Sci USA. 2011;108(40):16729-16734

11. Michels A, Zhang L, Khadra A, Kushner JA, Redondo MJ, Pietropaolo M. Prediction and prevention of type 1 diabetes: update on success of prediction and struggles at prevention. Pediatr Diabetes. 2015;16(7):465-484.

12. Michels AW. Targeting the trimolecular complex. Clin Immunol. 2013;149(3):339-344.

13. Bresson D, et al. Anti-CD3 and nasal proinsulin combination therapy enhances remission from recent-onset autoimmune diabetes by inducing Tregs. J Clin Invest. 2006;116(5):1371-1381.

14. Brusko T, Bluestone J. Clinical application of regulatory T cells for treatment of type 1 diabetes and transplantation. Eur $J$ Immunol. 2008;38(4):931-934.

15. You S, et al. Autoimmune diabetes onset results from qualitative rather than quantitative age-dependent changes in pathogenic T-cells. Diabetes. 2005;54(5):1415-1422.

16. Pietropaolo M, Surhigh JM, Nelson PW, Eisenbarth GS. Primer: immunity and autoimmunity. Diabetes. 2008;57(11):2872-2882.

17. Roep BO. The role of T-cells in the pathogenesis of Type 1 diabetes: from cause to cure. Diabetologia. 2003;46(3):305-321.

18. Ziegler AG, Nepom GT. Prediction and pathogenesis in type 1 diabetes. Immunity. 2010;32(4):468-478.

19. Morran MP, Vonberg A, Khadra A, Pietropaolo M. Immunogenetics of type 1 diabetes mellitus. Mol Aspects Med. 2015;42:42-60.

20. Mariño E, et al. Marginal-zone B-cells of nonobese diabetic mice expand with diabetes onset, invade the pancreatic lymph nodes, and present autoantigen to diabetogenic T-cells. Diabetes. 2008;57(2):395-404.

21. Hinman RM, Cambier JC. Role of B lymphocytes in the pathogenesis of type 1 diabetes. Curr Diab Rep. $2014 ; 14(11): 543$.

22. Noorchashm H, Noorchashm N, Kern J, Rostami SY, Barker CF, Naji A. B-cells are required for the initiation of insulitis and sialitis in nonobese diabetic mice. Diabetes. 1997;46(6):941-946.

23. Serreze DV, Fleming SA, Chapman HD, Richard SD, Leiter EH, Tisch RM. B lymphocytes are critical antigen-presenting cells for the initiation of T cell-mediated autoimmune diabetes in nonobese diabetic mice. J Immunol. 1998;161(8):3912-3918.

24. Pietropaolo M, Eisenbarth GS. Autoantibodies in human diabetes. Curr Dir Autoimmun. 2001;4:252-282.

25. Pescovitz MD, et al. Rituximab, B-lymphocyte depletion, and preservation of beta-cell function. N Engl J Med. 2009;361(22):2143-2152.

26. Yu L, et al. Rituximab selectively suppresses specific islet antibodies. Diabetes. 2011;60(10):2560-2565.

27. Kleffel S, et al. Interleukin-10+ regulatory B cells arise within antigen-experienced CD40+ B cells to maintain tolerance to islet autoantigens. Diabetes. 2015;64(1):158-171.

28. Montandon R, et al. Innate pro-B-cell progenitors protect against type 1 diabetes by regulating autoimmune effector T cells. Proc Natl Acad Sci USA. 2013;110(24):E2199-E2208.

29. Jeker LT, Bour-Jordan H, Bluestone JA. Breakdown in peripheral tolerance in type 1 diabetes in mice and humans. Cold Spring Harb Perspect Med. 2012;2(3):a007807.

30. Mariño E, Grey ST. B cells as effectors and regulators of autoimmunity. Autoimmunity. 2012;45(5):377-387.

31. Kubo M, Motomura Y. Transcriptional regulation of the anti-inflammatory cytokine IL-10 in acquired immune cells. Front Immunol. 2012;3:275.

32. Leiter EH. The NOD mouse: a model for insulin-dependent diabetes mellitus. Curr Protoc Immunol. 2001;Chapter 15:Unit 15.9.

33. Christianson SW, Shultz LD, Leiter EH. Adoptive transfer of diabetes into immunodeficient NOD-scid/scid mice. Relative contributions of CD4+ and CD8+ T-cells from diabetic versus prediabetic NOD.NON-Thy-1a donors. Diabetes. 1993;42(1):44-55.

34. Qin J, et al. Increased Circulating Th17 but Decreased CD4+Foxp3+ Treg and CD19+CD1dhiCD5+ Breg Subsets in New-Onset Graves' Disease. Biomed Res Int. 2017;2017:8431838.

35. Tedder TF. B10 cells: a functionally defined regulatory B cell subset. J Immunol. 2015;194(4):1395-1401.

36. Peng B, Ming Y, Yang C. Regulatory B cells: the cutting edge of immune tolerance in kidney transplantation. Cell Death Dis. 2018;9(2):109.

37. Taitano SH, van der Vlugt LEPM, Shea MM, Yang J, Lukacs NW, Lundy SK. Differential Influence on Regulatory B Cells by TH2 Cytokines Affects Protection in Allergic Airway Disease. J Immunol. 2018;201(7):1865-1874.

38. Walker LS, von Herrath M. CD4 T cell differentiation in type 1 diabetes. Clin Exp Immunol. 2016;183(1):16-29.

39. Haskins K, Cooke A. CD4 T cells and their antigens in the pathogenesis of autoimmune diabetes. Curr Opin Immunol. 2011;23(6):739-745.

40. Rabinovitch A, Suarez-Pinzon WL. Role of cytokines in the pathogenesis of autoimmune diabetes mellitus. Rev Endocr Metab Disord. 2003;4(3):291-299.

41. Ortis F, et al. Differential usage of NF- $\kappa B$ activating signals by IL-1 $\beta$ and TNF- $\alpha$ in pancreatic beta cells. FEBS Lett. 2012;586(7):984-989.

42. Kracker S, Durandy A. Insights into the B cell specific process of immunoglobulin class switch recombination. Immunol Lett. 2011;138(2):97-103.

43. Allman D, Pillai S. Peripheral B cell subsets. Curr Opin Immunol. 2008;20(2):149-157. 
44. Klinker MW, Lundy SK. Multiple mechanisms of immune suppression by B lymphocytes. Mol Med. 2012;18:123-137.

45. Mauri C, Menon M. The expanding family of regulatory B cells. Int Immunol. 2015;27(10):479-486.

46. Klinker MW, Reed TJ, Fox DA, Lundy SK. Interleukin-5 supports the expansion of fas ligand-expressing killer B cells that induce antigen-specific apoptosis of CD4(+) T cells and secrete interleukin-10. PLoS One. 2013;8(8):e70131.

47. Bélanger S, Crotty S. Dances with cytokines, featuring TFH cells, IL-21, IL-4 and B cells. Nat Immunol. 2016;17(10):1135-1136.

48. Rush JS, Hodgkin PD. B cells activated via CD40 and IL-4 undergo a division burst but require continued stimulation to maintain division, survival and differentiation. Eur J Immunol. 2001;31(4):1150-1159.

49. Shen P, Fillatreau S. Antibody-independent functions of B cells: a focus on cytokines. Nat Rev Immunol. 2015;15(7):441-451.

50. Arvan P, Pietropaolo M, Ostrov D, Rhodes CJ. Islet autoantigens: structure, function, localization, and regulation. Cold Spring Harb Perspect Med. 2012;2(8):a007658.

51. Fousteri G, Ippolito E, Ahmed R, Hamad ARA. Beta-cell Specific Autoantibodies: Are they Just an Indicator of Type 1 Diabetes? Curr Diabetes Rev. 2017;13(3):322-329.

52. Mann MK, Maresz K, Shriver LP, Tan Y, Dittel BN. B cell regulation of CD4+CD25+ T regulatory cells and IL-10 via B7 is essential for recovery from experimental autoimmune encephalomyelitis. J Immunol. 2007;178(6):3447-3456.

53. Matsushita T, et al. Inhibitory role of CD19 in the progression of experimental autoimmune encephalomyelitis by regulating cytokine response. Am J Pathol. 2006;168(3):812-821.

54. Matsushita T, Horikawa M, Iwata Y, Tedder TF. Regulatory B cells (B10 cells) and regulatory T cells have independent roles in controlling experimental autoimmune encephalomyelitis initiation and late-phase immunopathogenesis. J Immunol. 2010;185(4):2240-2252.

55. Carter NA, Rosser EC, Mauri C. Interleukin-10 produced by B cells is crucial for the suppression of Th17/Th1 responses, induction of T regulatory type 1 cells and reduction of collagen-induced arthritis. Arthritis Res Ther. 2012;14(1):R32.

56. Lundy SK, Klinker MW. Characterization and activity of Fas ligand producing CD5+ B cells. Methods Mol Biol. 2014;1190:81-102.

57. Lundy SK, Klinker MW, Fox DA. Killer B lymphocytes and their fas ligand positive exosomes as inducers of immune tolerance. Front Immunol. 2015;6:122.

58. Vudattu NK, Herold KC. Treatment of new onset type 1 diabetes with teplizumab: successes and pitfalls in development. Expert Opin Biol Ther. 2014;14(3):377-385.

59. Krishnamurthy B, Selck C, Chee J, Jhala G, Kay TW. Analysis of antigen specific T cells in diabetes - Lessons from pre-clinical studies and early clinical trials. J Autoimmun. 2016;71:35-43.

60. You S, Chatenoud L. Autoimmune Diabetes: An Overview of Experimental Models and Novel Therapeutics. Methods Mol Biol. 2016;1371:117-142

61. Serreze DV, et al. B lymphocytes are essential for the initiation of T cell-mediated autoimmune diabetes: analysis of a new "speed congenic" stock of NOD.Ig mu null mice. J Exp Med. 1996;184(5):2049-2053.

62. Akashi T, et al. Direct evidence for the contribution of B cells to the progression of insulitis and the development of diabetes in non-obese diabetic mice. Int Immunol. 1997;9(8):1159-1164.

63. Wong FS, Visintin I, Wen L, Granata J, Flavell R, Janeway CA. The role of lymphocyte subsets in accelerated diabetes in nonobese diabetic-rat insulin promoter-B7-1 (NOD-RIP-B7-1) mice. J Exp Med. 1998;187(12):1985-1993.

64. Yang M, Rui K, Wang S, Lu L. Regulatory B cells in autoimmune diseases. Cell Mol Immunol. 2013;10(2):122-132.

65. Haller MJ, et al. Anti-thymocyte globulin/G-CSF treatment preserves $\beta$ cell function in patients with established type 1 diabetes J Clin Invest. 2015;125(1):448-455.

66. Shevach EM, Thornton AM. tTregs, pTregs, and iTregs: similarities and differences. Immunol Rev. 2014;259(1):88-102.

67. O'Garra A, Vieira PL, Vieira P, Goldfeld AE. IL-10-producing and naturally occurring CD4+ Tregs: limiting collateral damage. J Clin Invest. 2004;114(10):1372-1378.

68. Russell MA, Morgan NG. The impact of anti-inflammatory cytokines on the pancreatic $\beta$-cell. Islets. 2014;6(3):e950547.

69. Asadullah K, Sterry W, Volk HD. Interleukin-10 therapy--review of a new approach. Pharmacol Rev. 2003;55(2):241-269.

70. Tedder TF, Leonard WJ. Autoimmunity: regulatory B cells--IL-35 and IL-21 regulate the regulators. Nat Rev Rheumatol. 2014;10(8):452-453

71. Yang M, et al. Novel function of B cell-activating factor in the induction of IL-10-producing regulatory B cells. J Immunol. 2010;184(7):3321-3325

72. Hua C, et al. A proliferation inducing ligand (APRIL) promotes IL-10 production and regulatory functions of human B cells. J Autoimmun. 2016;73:64-72.

73. Mion F, Tonon S, Toffoletto B, Cesselli D, Pucillo CE, Vitale G. IL-10 production by B cells is differentially regulated by immune-mediated and infectious stimuli and requires p38 activation. Mol Immunol. 2014;62(2):266-276.

74. Mathieu O, Picot MC, Gelisse P, Breton H, Demoly P, Hillaire-Buys D. Effects of carbamazepine and metabolites on IL-2, IL-5, IL-6, IL-10 and IFN- $\gamma$ secretion in epileptic patients: the influence of co-medication. Pharmacol Rep. 2011;63(1):86-94

75. Davalli AM, Perego C, Folli FB, Bosi E. Long-lasting remission of type 1 diabetes following treatment with topiramate for generalized seizures. Acta Diabetol. 2012;49(1):75-79.

76. Lu L, Yoshimoto K, Morita A, Kameda H, Takeuchi T. Bendamustine increases interleukin-10 secretion from B cells via p38 MAP kinase activation. Int Immunopharmacol. 2016;39:273-279.

77. Poe JC, Hasegawa M, Tedder TF. CD19, CD21, and CD22: multifaceted response regulators of B lymphocyte signal transduction. Int Rev Immunol. 2001;20(6):739-762.

78. Di Caro V, Phillips B, Engman C, Harnaha J, Trucco M, Giannoukakis N. Involvement of suppressive B-lymphocytes in the mechanism of tolerogenic dendritic cell reversal of type 1 diabetes in NOD mice. PLoS One. 2014;9(1):e83575.

79. Cabrera SM, et al. Interleukin-1 antagonism moderates the inflammatory state associated with Type 1 diabetes during clinical trials conducted at disease onset. Eur J Immunol. 2016;46(4):1030-1046.

80. Moran A, et al. Interleukin-1 antagonism in type 1 diabetes of recent onset: two multicentre, randomised, double-blind, placebo-controlled trials. Lancet. 2013;381(9881):1905-1915.

81. Jenkins JK, Malyak M, Arend WP. The effects of interleukin-10 on interleukin-1 receptor antagonist and interleukin-1 beta production in human monocytes and neutrophils. Lymphokine Cytokine Res. 1994;13(1):47-54. 
82. Gopinathan U, et al. Global effect of interleukin-10 on the transcriptional profile induced by Neisseria meningitidis in human monocytes. Infect Immun. 2012;80(11):4046-4054.

83. Stumpf M, Zhou X, Bluestone JA. The B7-independent isoform of CTLA-4 functions to regulate autoimmune diabetes. J Immunol. 2013;190(3):961-969.

84. Tuttle AH, et al. Immunofluorescent detection of two thymidine analogues (CldU and IdU) in primary tissue. $J$ Vis Exp. 2010;(46):2166.

85. Cox AR, et al. Resolving Discrepant Findings on ANGPTL8 in $\beta$-Cell Proliferation: A Collaborative Approach to Resolving the Betatrophin Controversy. PLoS One. 2016;11(7):e0159276.

86. Peto R, Peto J. Asymptotically Efficient Rank Invariant Test Procedures. J R Stat Soc Series A Gen. 1972;135(2):185-207. 